\title{
Fecal Microbial Transplantation and Its Potential Application in Cardiometabolic Syndrome
}

\author{
Avner Leshem ${ }^{1,2 \dagger}$, Nir Horesh ${ }^{1,3 \dagger}$ and Eran Elinav ${ }^{1,4 *}$ \\ ${ }^{1}$ Immunology Department, Weizmann Institute of Science, Rehovot, Israel, ${ }^{2}$ Department of Surgery, Tel Aviv Sourasky \\ Medical Center, Tel Aviv, Israel, ${ }^{3}$ Department of General Surgery B and Organ Transplantation, Sheba Medical Center, \\ Ramat Gan, Israel, ${ }^{4}$ Cancer-Microbiome Division, Deutsches Krebsforschungszentrum (DKFZ), Heidelberg, Germany
}

\section{OPEN ACCESS}

Edited by:

Nancie J. Maclver,

Duke University, United States

Reviewed by:

Christopher Staley,

University of Minnesota Twin Cities,

United States

Anna Maria Seekatz,

Clemson University, United States

*Correspondence:

Eran Elinav

eran.elinav@weizmann.ac.il; e.elinav@dkfz-heidelberg.de

tThese authors have contributed equally to this work

Specialty section:

This article was submitted to Nutritional Immunology, a section of the journal Frontiers in Immunology

Received: 28 March 2019

Accepted: 28 May 2019

Published: 14 June 2019

Citation:

Leshem A, Horesh N and Elinav E (2019) Fecal Microbial Transplantation and Its Potential Application in

Cardiometabolic Syndrome.

Front. Immunol. 10:1341.

doi: 10.3389/fimmu.2019.01341
Newly revealed links between inflammation, obesity, and cardiometabolic syndrome have created opportunities to try previously unexplored therapeutic modalities in these common and life-risking disorders. One potential modulator of these complex disorders is the gut microbiome, which was described in recent years to be altered in patients suffering from features of cardiometabolic syndrome and to transmit cardiometabolic phenotypes upon transfer into germ-free mice. As a result, there is great interest in developing new modalities targeting the altered commensal bacteria as a means of treatment for cardiometabolic syndrome. Fecal microbiota transplantation (FMT) is one such modality in which a disease-associated microbiome is replaced by a healthy microbiome configuration. So far clinical use of FMT has been overwhelmingly successful in recurrent Clostridium difficile infection and is being extensively studied in other microbiome-associated pathologies such as cardiometabolic syndrome. This review will focus on the rationale, promises and challenges in FMT utilization in human disease. In particular, it will overview the role of the gut microbiota in cardiometabolic syndrome and the rationale, experience, and prospects of utilizing FMT treatment as a potential preventive and curative treatment of metabolic human disease.

Keywords: FMT, fecal microbiome transplantation, cardiometabolic disease, microbiome, microbiota

\section{CARDIOMETABOLIC SYNDROME}

Cardiometabolic syndrome (also termed "Metabolic syndrome") consists of the co-occurrence of a cluster of pathogenically-associated metabolic disorders including obesity, insulin resistance, non-alcoholic fatty liver disease, hypertension, and hypercholesterolemia. When present, the combined effect of these disorders significantly increases the risk of developing cardiovascular disease and type 2 Diabetes Mellitus (TIIDM) (1). It is estimated that $22 \%$ of the adult population in the US suffers from cardiometabolic syndrome and prevalence is on the rise, especially in patients older than 60 years old where prevalence is $43.5 \%(2-4)$. The clinical implications of cardiometabolic syndrome are predominantly related to the increased risk of developing cardiovascular complications of atherosclerosis and micro- or macrovascular complications of TIIDM. Several studies estimated that the relative risk (RR) for developing cardiovascular disease is double than the general population ( $\mathrm{RR}=1.53-2.18)$ in patients suffering from cardiometabolic syndrome (5-7), coupled with an increase in all-cause mortality $(R R=1.27-1.6)$. In addition, the relative risk of developing TIIDM was significantly higher in patients suffering from other features of cardiometabolic disease ( $\mathrm{RR}=3.53-5.17)$ as compared to the general population (8). 
In addition to the above metabolic and cardiovascular complications, cardiometabolic syndrome is associated with an aberrant inflammatory and coagulative response, including increased levels of proinflammatory markers including CReactive Protein, interleukin (IL)-6, and plasminogen activator inhibitor (PAI)-1 (9-13). Although these inflammatory and prothrombotic markers were shown to be associated with an increased risk of cardiovascular disease and TIIDM, the exact mechanisms by which they act to increase this risk remain unclear. In recent years there is increasing evidence that these inflammatory processes might be related to an imbalance in the immunologic response of the host in relation to host microbiota (14-16).

\section{THE GUT MICROBIOTA}

The commensal gut microbiota is a "signaling hub" in many physiological functions of the mammalian host and especially in host's metabolism (17). A staggering amount of scientific evidence was gathered on the potential role of the commensal microbiota in influencing human health $(18,19)$ and a variety of multi-factorial diseases like Inflammatory bowel disease (IBD) (20, 21), Irritable bowel syndrome (IBS) $(22,23)$, and gastrointestinal cancer (24-26). The gut microbiota was also shown to have significance in non-gastrointestinal conditions such as cardiometabolic $(27,28)$, neurologic (29), and even psychiatric disorders (30-32).

There is great need to deepen the mechanistic understanding of commensal microbiota along with their function, secreted molecules repertoire, and their precise impacts on the host. An approach which favors mechanisms over correlations is much more likely to illuminate therapeutic targets for preventing or treating microbiota-associated diseases by means of antibiotics, prebiotics, probiotics, and fecal microbial transplants. While antibacterial treatment (such as antibiotics) has profound effects on the gut microbiota (33), it is non-specific and associated with the emergence of resistant strains, which precludes it from being a safe long-term microbiome intervention in chronic disease. Some nutritional interventions are known to affect cardiometabolic diseases including TIIDM and obesity by targeting the gut microbiota (34-36). Examples of dietary interventions include prebiotics, substances that include dietary fibers and oligosaccharides, which were suggested to have a potential beneficial effect on human health that is also correlated with alternations in gut microbiota (37). Probiotics, available in multiple food formulations, are aimed at modulating the host and its microbiome. However, there is contradicting evidence as to the beneficial effect that probiotics have on human health, with large-scale, non-industry sponsored high-quality clinical trials still missing for the majority of claimed indications $(38,39)$. Other experimental microbiome interventions include "postbiotic" treatment, utilizing microbiome-modulated metabolites as means of treatment (40,41). Phage therapy is emerging as a promising pathobiont-eradicating therapeutic modality (42-44). Although bacteriophages, i.e., viruses that exclusively infect specific bacteria, are mostly studied in the context of treating antibiotic-resistant infections (45-47), their potential to specifically target bacterial strains may be harnessed to manipulate the gut microbiota to a more metabolically healthy composition $(48,49)$. Additionally, an intervention targeting the host interface of the host-microbiome gut niche may diminish some deleterious inflammatory consequences of obesity and diabetes (50).

\section{FECAL MICROBIOTA TRANSPLANTATION}

Replacement of the indigenous microbiome of patients afflicted with microbiota-associated diseases with a "healthy" microbial configuration was termed "Fecal Microbiota Transplantation" (FMT) and is emerging as a new therapeutic method for various microbiota-associated pathological conditions. The process involves the collection of filtered stools collected from either a healthy donor or from the recipient himself (autologous FMT) at a time point prior to initiation of disease and associated dysbiosis and its instillation into the intestinal tract of a patient suffering from a certain medical condition. In most of the below review, we will refer to FMT performed by microbiome transfer across different individuals. So far, the therapeutic efficacy of FMT has been overwhelmingly significant in Clostridium difficile infection and recently in some studies in Ulcerative Colitis, but is proving to be much more challenging in other complex human conditions.

The use of feces transferred from healthy donors in treating patients suffering from diarrhea dates back to ancient Chinese medicine, nearly 1700 years ago (51). Modern era use of FMT was first described by Eiseman et al. (52) as an adjunct treatment for patients with antibiotic-associated diarrhea and was administrated to recipients via retention enemas (52). Despite the empiric success of the treatment, the etiology of postantibiotic colitis (commonly termed today "pseudomembranous colitis") remained unknown for nearly 20 years following that report when it was found that toxins from $C$. difficile, an anaerobic commensal bacterium, were responsible for the pathologic process $(53,54)$. Following these revelations a plethora of evidence of varying quality demonstrated the clinical effect that FMT has on pseudomembranous colitis, culminating with a landmark randomized clinical trial demonstrating the significant superiority that FMT has on recurrent $C$. difficile infection over the standard antibiotic treatment (55). This seminal study featured an overall $90 \%$ success rate of FMT as treatment of recurrent $C$. difficile infection and was terminated prematurely given these dramatic interim analysis results.

Figure 1 lists other medical conditions in which the efficacy of FMT is currently being clinically investigated. Many of the associated studies assessing these various indications are rather preliminary, thereby tending to be very heterogeneous in their design (i.e., inclusion criteria, treatment protocol, etc.). For example, FMT for Ulcerative Colitis has been tested in a few randomized controlled trials, some of which demonstrated clinical efficacy (56-58) while other studies failed to document such effect (59). FMT in Crohn's disease was evaluated mainly in small case series and has been proven to be more 


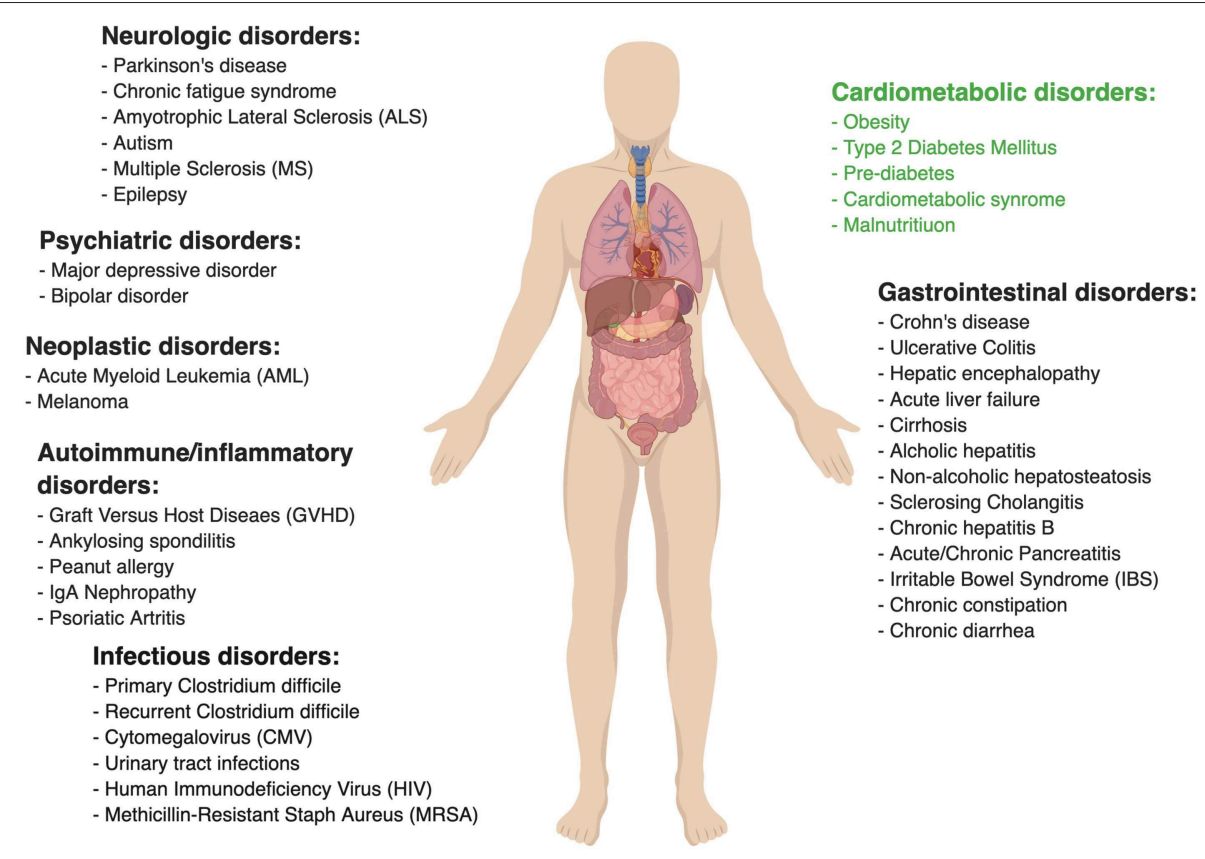

FIGURE 1 | Ongoing clinical trials to evaluate fecal microbial transplant. Data taken from www.clinicaltrial.gov. Search words: fecal microbial transplant/FMT.

challenging, potentially because of pathophysiological differences from Ulcerative Colitis giving rise to technical difficulties (such as retention enema not reaching the site of active inflammation in small intestinal Crohn's disease). One study of 30 patients with refractory Crohn's disease noted promising results of $86.7 \%$ clinical remission in the first year following treatment and $76.7 \%$ remission rate in the second year (60), however, another study failed to reach such results (61).

Primary sclerosing cholangitis (PSC) is an auto-inflammatory disorder of the bile ducts and is associated with IBD, dysbiosis, and interrupted barrier function (62). A recent small uncontrolled clinical study in 10 PSC patients, has demonstrated FMT to improve bacterial diversity and Alkaline phosphatase (a disease-severity surrogate marker) levels, however, no other clinically meaningful disease parameters were reported to improve (63). IBS was also suggested to improve after FMT in a recent randomized controlled study including 90 patients, demonstrating that $65 \%$ of patients had symptomatic relief with FMT vs. $43 \%$ in the placebo group ( $p=0.049$ ) (64). Despite these encouraging results, a smaller scale randomized trial reported contradicting results favoring the placebo group (65), adding to the controversy surrounding FMT as a therapeutic measure in IBS. Considering these scarce evidence and in spite being microbiome-associated diseases, FMT in Crohn's disease, PSC, and IBS remains investigational as of now.

\section{FMT IN CARDIOMETABOLIC SYNDROME-PRECLINICAL RESEARCH}

Investigational use of FMT from mouse or human origin, transferred into germ-free (GF) mice which are completely devoid of a microbiome, has greatly advanced our understanding of the gut microbiome's causal roles in contributing and regulating cardiometabolic syndrome (Table 1). GF mice suffer of multiple metabolic alterations. Upon "conventionalizing” GF mice by transplantation of microbiota from regular wild-type mice they gain weight and their insulin sensitivity decreases back to normal levels (73). When GF mice are colonized with fecal microbiota from obese mice they gain even more weight and develop features of cardiometabolic syndrome, probably due to increased energy harvest from the diet $(66,72,74)$. Some reports suggest that GF mice are resilient to diet-induced obesity by means of high-fat diet feeding (75-77), but others dispute these claims (78-83). These conflicting reports may stem from experimental differences in dietary macronutrients, namely fat/protein/fibers source and content $(77,84,85)$.

Another pre-clinical example of the potential utilization of FMT in metabolic disease involves essential hypertension, which is considered a common feature of cardiometabolic syndrome spectrum. Metagenomic and metabolomic analyses of stools from 99 individuals with hypertension in comparison to samples from 56 subjects with pre-hypertension and 41 healthy individuals revealed that the microbiome of pre-hypertension subjects was more similar to that of hypertensive patients, and was associated with decreased microbial diversity (71). When hypertensive patients' feces were transferred to GF mice, the blood pressure of recipient mice had increased in comparison to GF recipients of healthy donor microbiome. Elevation of blood pressure following FMT was also reported in conventional mice recipients (86). Altogether these results suggest an important role of the gut microbiota in hypertension development, however, the lack of human data and mechanistic explanations for such a role necessitates additional investigation. 
TABLE 1 | Gut microbiota modulation in cardiometabolic syndrome.

\begin{tabular}{|c|c|c|c|c|}
\hline Source & Subjects & Main findings & Strengths & Limitations \\
\hline \multicolumn{5}{|c|}{ ADIPOSITY AND OBESITY } \\
\hline Turnbaugh et al. (66) & Humans Mice & $\begin{array}{l}\text { Obesity is associated with a distinct } \\
\text { microbiome with a high capacity to } \\
\text { harvest energy from food. }\end{array}$ & Human microbiome functional analysis & $\begin{array}{l}\text { Pre-clinical } \\
\text { No mechanism proposed }\end{array}$ \\
\hline Thaiss et al. (40) & Mice & $\begin{array}{l}\text { A post-dieting associated microbiome that } \\
\text { persists during successful dieting, } \\
\text { contributes to post-dieting weight-regain } \\
\text { in a flavonoid-dependent manner. }\end{array}$ & $\begin{array}{l}\text { Metabolomic analysis Human microbiome } \\
\text { functional analysis A mechanism } \\
\text { is proposed }\end{array}$ & Pre-clinical \\
\hline Ridaura et al. (67) & Humans Mice & $\begin{array}{l}\text { Obesity is transferrable upon FMT from } \\
\text { obese humans to mice. Co-housing } \\
\text { recipients of obese microbiome with } \\
\text { recipients of lean microbiome, prevented } \\
\text { weight gain, and microbiome of all } \\
\text { co-housed mice resembled "lean" } \\
\text { configuration. }\end{array}$ & Weight discordant twins as controls & $\begin{array}{l}\text { Pre-clinical } \\
\text { No mechanism proposed }\end{array}$ \\
\hline Tremaroli et al. (68) & Humans Mice & $\begin{array}{l}\text { Obese humans who underwent bariatric } \\
\text { surgery experienced long-term } \\
\text { weight-loss and reduction in TMAO levels } \\
\text { accompanied by microbiome composition } \\
\text { shift. FMT to GF mice resulted in reduced } \\
\text { adiposity. }\end{array}$ & $\begin{array}{l}\text { Human samples Microbiome } \\
\text { functional analysis Bile acid analysis }\end{array}$ & $\begin{array}{l}\text { No different in net weight gain } \\
\text { No insulin sensitivity assessment }\end{array}$ \\
\hline \multicolumn{5}{|c|}{ GLUCOSE METABOLISM } \\
\hline Reijnders et al. (69) & Humans & $\begin{array}{l}\text { A } 7 \text { days course of either Vancomycin or } \\
\text { Amoxicillin did not affect host metabolism } \\
\text { in overweight or obese adults, despite } \\
\text { altered microbial composition, after } 8 \\
\text { weeks from treatment initiation. }\end{array}$ & $\begin{array}{l}\text { Randomized placebo-controlled Double } \\
\text { blinded-8 weeks follow-up }\end{array}$ & $\begin{array}{l}\text { Short antibiotic exposure } \\
\text { Small sample }(N=56)\end{array}$ \\
\hline Vrieze et al. (70) & Humans & $\begin{array}{l}\text { A } 7 \text { days course of oral Vancomycin in } \\
\text { metabolic syndrome patients decreased } \\
\text { fecal microbial diversity and fecal } \\
\text { secondary bile acids, increased plasma } \\
\text { primary bile acids, and decreased insulin } \\
\text { sensitivity. A } 7 \text { day course of Amoxicillin } \\
\text { did not affect any of these parameters. }\end{array}$ & Randomized controlled trial & $\begin{array}{l}\text { Short antibiotic exposure } \\
\text { Single blinded } \\
\text { Short follow-up (1 week) } \\
\text { Modest effect size } \\
\text { Significance was marginal } \\
\text { Small sample }(N=20) \\
\text { No placebo } \\
\text { No microbial functional analysis }\end{array}$ \\
\hline Zeevi et al. (36) & Humans & $\begin{array}{l}\text { Post-prandial glycemic response to } \\
\text { different foods is individual and can be } \\
\text { predicted based on clinical and microbial } \\
\text { parameters. }\end{array}$ & $\begin{array}{l}\text { Human study Large sample size }(N=900) \\
\text { Validation cohort }\end{array}$ & $\begin{array}{l}\text { Use of stool samples } \\
\text { Focused on glycemic response } \\
\text { Microbiome contribution to } \\
\text { glycemic prediction isn't clear }\end{array}$ \\
\hline \multicolumn{5}{|l|}{ HYPERTENSION } \\
\hline Li et al. (71) & Humans Mice & $\begin{array}{l}\text { The gut microbiome of hypertensive } \\
\text { patients is distinct, and hypertension is } \\
\text { transferable upon FMT. }\end{array}$ & $\begin{array}{l}\text { Large human cohort }(N=196) \\
\text { Metabolomic analysis }\end{array}$ & No mechanism proposed \\
\hline \multicolumn{5}{|c|}{ METABOLIC SYNDROME } \\
\hline Vijay-Kumar et al. (72) & Mice & $\begin{array}{l}\text { TLR5 KO leads to hyperlipidemia, } \\
\text { hypertension, insulin resistance } \\
\text { accompanied by microbial composition } \\
\text { shift and is transferrable to WT GF mice } \\
\text { upon FMT. }\end{array}$ & Wide metabolic assessment & \\
\hline
\end{tabular}

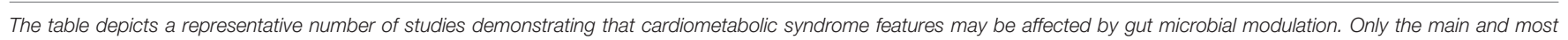
relevant findings, limitations, and strengths are presented.

Likewise, GF mice fecal transfer experiments also suggest that the gut microbiome may modulate insulin sensitivity in various contexts $(87,88)$, weight gain $(40)$, and fatty liver (40). Interestingly, this approach suggested a causal role of the gut microbiota in modulating the activity of Metformin, a medication used as first-line treatment for diabetes. In spite of this drug's extensive clinical use, the mechanism by which it increases insulin sensitivity remained elusive. Who et al. carried out a randomized placebo-controlled clinical trial of 4 months of Metformin vs. placebo in 40 treatmentnaïve diabetic patients, to show that Metformin alters the gut microbiota (89). They further showed that the transfer of 
Metformin-altered human microbiota to GF mice improved recipients' insulin sensitivity. In a subsequent study Sun et al. utilized a metagenomic and metabolomic analysis to probe the mechanism behind microbiome-dependent metformin activity. They revealed that newly diagnosed diabetic patients who started treatment with metformin, experienced a decrease in Bacteroides fragilis abundance accompanied by an increase in a specific bile acid (glycoursodeoxycholic acid, GUDCA) (90). These changes were associated with inhibition of Farnesoid-X receptor (FXR) signaling, a receptor known to have a large impact on metabolic functions such as insulin sensitivity (Figure 2) (94). Both B. fragilis colonization and FXR knock-out abrogated Metformin's beneficial effect on insulin resistance. Finally, fecal microbial transplant from diabetic patients receiving Metformin improved insulin sensitivity in conventionally-raised antibiotic-treated mice compared to transplant from treatment-naïve diabetic patients. Altogether, these studies suggest that Metformin has a prebiotic quality $(89,90)$.

FMT of human microbiome configurations into GF mice was also used to show a causal role of the gut microbiome in mediating the beneficial effect of bariatric surgeries, which were originally designed to treat morbid obesity, but were also found to be extremely effective in also treating other cardiometabolic syndrome disorders such as insulin resistance and TIIDM (9597). Results from studies utilizing rodent models of bariatric surgery have suggested a causal role of the gut microbiome in the metabolic beneficial effects of bariatric surgery (98-103). In one study, GF mice who were treated with fecal microbiome from previously obese patients who underwent bariatric surgery exhibited decreased adiposity compared with mice colonized with the microbiota of obese patients. In two additional studies, GF mice who received FMT from previously-obese rodents who underwent bariatric surgery also demonstrated weight loss and improved insulin sensitivity $(100,104)$, however, the observed improvements were very mild. Although these findings suggest a prebiotic mechanism of bariatric surgeries, the role of gut microbiota in post-bariatric surgery metabolic improvement warrants further inquiry. More importantly, revealing the mechanisms governing it is of special interest as it may lead to new therapeutic targets in cardiometabolic syndrome treatment as an alternative to a risky invasive procedure.

An optimized controlled methodology that served to disentangle genetic and environmental impacts on the microbiome while highlighting its impact on metabolic health involves characterization of the microbiome of siblings including twins, and their FMT into GF mice. Twins, sharing similar genetics and early-life environmental exposures, have relatively similar microbiome compositions $(105,106)$. One group performed FMT with microbiota from pairs of weightdiscordant twins into separate groups of GF mice and measured their adiposity by quantitative magnetic resonance imaging (67). GF mice recipients of obese-twin microbiome developed increased adiposity independently of food intake. Interestingly, a repeat of the same experiment while co-housing recipients of microbiota from both lean and obese donors (in which coprophagy leads to equilibration of microbiome configuration) resulted in the loss of adiposity in both recipient groups, which under this equilibration setting were found to harbor a "lean" microbiome. These results of both transmissible adiposity phenotype of weight-discordant twins and lean-microbiome dominance upon co-housing were later confirmed by other independent groups $(67,107)$.

Preclinical data from FMT experiments into none-GF animals also support a significant role of the gut microbiome in cardiometabolic disease. Microbiome depletion by means of broad-spectrum antibiotics exposure improved insulinresistance in conventional mice fed obesogenic diet (108). Rats fed with fructose-reach diet developed cardiometabolic syndrome that was improved upon FMT from rats fed normal chow (109). Resveratrol is a substance produced by plants in response to stress and is believed to have beneficial effects in cardiometabolic syndrome $(110,111)$. FMT from Resveratroltreated donor mice improved insulin resistance in recipient mice (112). A recent study by the same group recapitulated the same phenotype with respect to insulin resistance and also showed improvement in hypertension in recipient mice (86). Interestingly, this effect was also evident when obese recipient mice were given heat-killed FMT, suggesting the presence of metabolites, non-bacterial microbes that survived heat killing, or non-viable bacterial components may mediate the beneficial effect. Strikingly, FMT from Resveratrol-treated mice was even more effective than direct Resveratrol supplementation.

With these encouraging preclinical data notwithstanding, data from preclinical models should always be treated with "a grain of salt" since very frequently preclinical evidence fails to be translated into advancements in human clinical care. Limitations in that regards include species specificity in the colonization of some microbial strains, differences in sample preparation and storage between studies, inherent physiological differences between mice and humans with regard to microbiome composition and function, bowel transit time, and other gastrointestinal physiological features.

\section{FMT IN CARDIOMETABOLIC SYNDROME-CLINICAL RESEARCH}

Data to support the role of FMT in humans suffering from features of cardiometabolic syndrome is limited, but preliminary studies who mainly focused on one feature of cardiometabolic syndrome, insulin resistance, show promising preliminary results suggesting that FMT may favorably impact some metabolic features in humans. A landmark study randomly assigned 18 treatment-naïve male cardiometabolic syndrome patients to receive a single duodenal infusion of either allogeneicFMT from a lean healthy donor or autologous-FMT, i.e., their own stool as placebo equivalent (14). Six weeks after the infusion peripheral insulin sensitivity improved only in recipients of healthy donor microbiota. This change was also accompanied by an increase in bacterial diversity, a measure of "microbiome quality," and in butyrate-producing bacterial species who are suggested to exert a beneficial metabolic effect on mammalian hosts [Figure 2; $(113,114)$ ]. The strengths of the study were the randomized double-blind design, the 


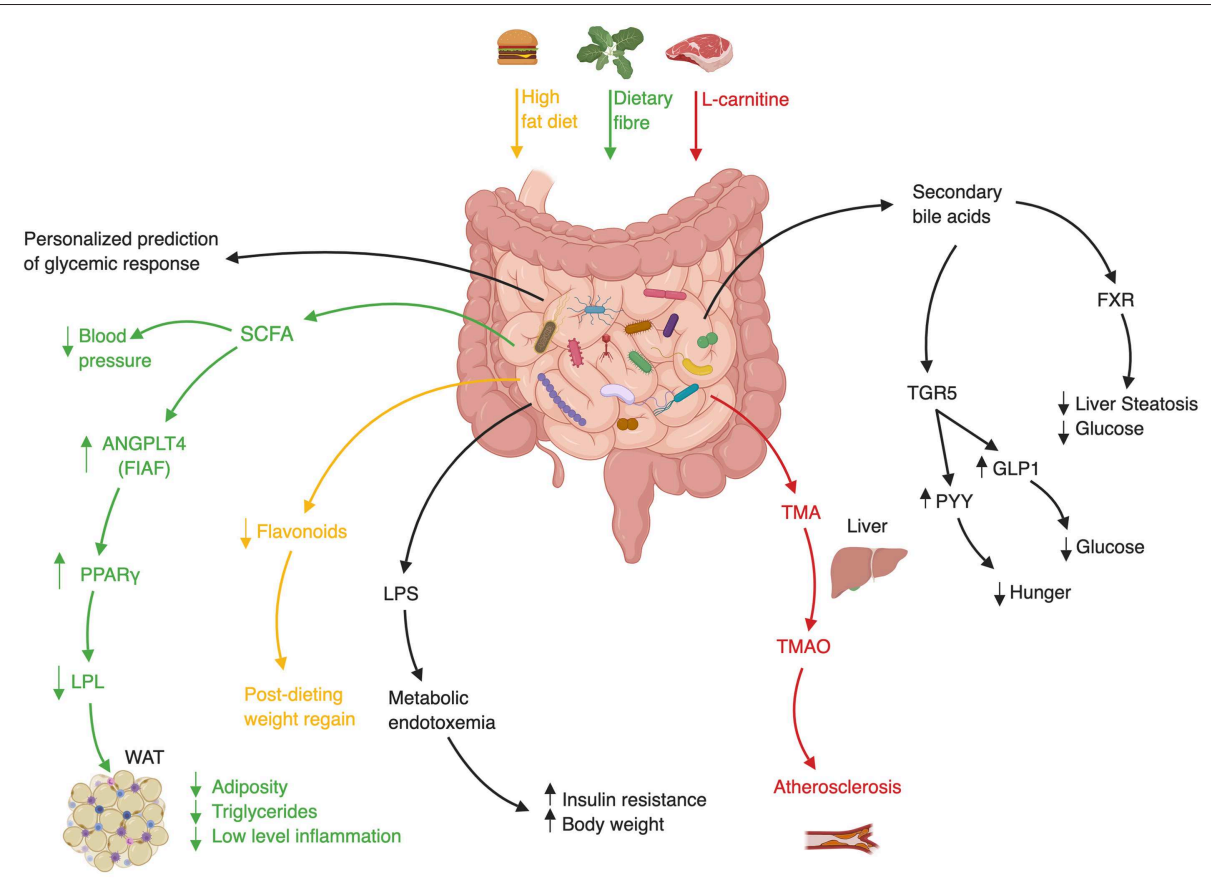

FIGURE 2 | Mechanisms of Gut Microbiota involvement in Cardiometabolic Syndrome. ANGPLT4-Angiopoietin-like 4, FIAF-Fast Induced Adipose Factor, FXR-Farnesoid-X Receptor, GLP1-Glucagon-like Peptide 1, LPL-Lipoprotein Lipase, LPS-Lipopolysaccharide, PPAR $\gamma$-Peroxisome proliferator-activated receptor $\gamma$, PYY-Peptide YY, SCFA-Short Chain Fatty Acid, TMA-Trimethylamine, TMAO-Trimethylamine-N Oxidase, WAT-White Adipose Tissue (36, 40, 91-93).

evaluation of microbial parameters before and after treatment, and the evaluation of these parameters in the small intestine which is often overlooked owing to technical difficulties. The main limitations of the study were the modest effect size of the investigated intervention, its small samples size and shortterm follow-up, the inclusion of males only, the non-anaerobic preparation of donor's fecal samples which may have impaired their quality, and the use of a relatively shallow characterization of microbial composition without a functional metagenomic analysis. Nonetheless, this was the first randomized study in humans suggesting that the gut microbiome may improve insulin sensitivity.

In a sequel trial, the same group of investigators subsequently randomized 38 obese male patients with cardiometabolic syndrome to receive either allogeneic-FMT from lean donors $(n=26)$ or autologous-FMT $[n=12 ;(115)]$. At 6 weeks following FMT, they observed a significant shift in both fecal and duodenal microbial composition, which was accompanied by an improvement in peripheral insulin sensitivity. Importantly, these changes were observed in only half of the treatment group while the other half did not exhibit either microbial shift or change in insulin sensitivity. Interestingly, at 18 weeks following FMT the recipients' fecal and duodenal microbial composition returned to baseline and so did their insulin sensitivity. This transient effect of FMT on insulin sensitivity supports a role of the gut microbiome in human insulin sensitivity. Further analysis revealed that response to leanFMT was largely dependent on recipients' and not donors' baseline characteristics, and more specifically the recipients' initial microbiome diversity. Of note, the study featured a longer follow up of four and a half months, larger sample size and the comparison of single vs. double FMT administrations (no difference was found between them). This study highlights the complex issue of "colonization resistance" and raises the issue of whether it is driven by the endogenous microbiome (116) or the host's immune system (117), as well as the issue of donor selection which comprise a major hurdle in FMTbased therapy.

A third trial assessed the impact of FMT on atherosclerosis. Trimethylamine-N-oxide (TMAO) is a microbiome-related metabolite that was shown to be associated with atherosclerosis and increased cardiovascular risk (118-120). Red meat contains high amounts of L-carnitine which is converted by members of the gut microbiome to TMA, which after its absorption in the intestine is converted in the liver to TMAO (Figure 2). Interestingly, a vegan diet selects for bacteria with low capacity to metabolize L-carnitine, resulting in vegans having a lower amount of circulating TMAO (119). In a small randomized double-blind pilot trial carried out by the same group of investigators, TMAO production and vascular inflammation were evaluated, in 20 obese male patients suffering from cardiometabolic syndrome who received either allogeneicFMT $(n=10)$ from a vegan donor or autologous-FMT $[n=10 ;(121)]$. Although vegan-donor FMT induced a shift toward vegan-like gut microbiome in some but not all recipients, this shift was not translated into beneficial effects on surrogate markers of arterial inflammation and atherogenicity. Further clinical trials to evaluate the efficacy 
of FMT in improving insulin resistance and obesity are currently underway.

\section{CHALLENGES AND LIMITATIONS IN FMT IMPLEMENTATION}

This apparent lack of comprehensive reproducible evidence to the efficacy of FMT in most indications, including cardiometabolic disease, may stem from several conceptual and methodological reasons.

\section{Donor Selection and Preparation}

Donor selection and preparation results from multiple studies suggest that responsiveness to FMT is, to a large extent, dependent on the donor, highlighting the importance of donor selection (Box 1). Selecting donors is a difficult task both because the gut microbiota is a complex entity making its quality-control challenging, and because infectious screening to prevent the transfer of communicable diseases from donor to recipient is costly, limited and debatable (122-125). Interindividual differences in microbiome composition are vast and the interaction between the donor's microbial strains and metabolites and the recipient's endogenous microbiome and immune system remain elusive and may prevent effective colonization, stabilization, and function in an unpredictable manner. Monitoring the co-existence of donor and recipient strains following FMT recently revealed that new donor-derived strains are less likely to colonize the recipient's gut than strains that already exist in the recipient, shifting the focus from "donorselection" to proper "donor-recipient matching" (117). In the very early days of modern FMT, recruited donors were mostly among family relatives of recipients, based on the hypothesis that shared environment and genetics promote similar microbial configuration which will facilitate colonization and thus improve treatment efficacy (126). However, although early reports favored family-relative donors $(127,128)$, more recent studies aimed directly to compare between related and unrelated healthy donor volunteers, showed no advantage to any group over the other (129-133). Since diet is known to be a major environmental influence on the gut microbiome, some investigators used a donor selecting strategy based on their diet (121).

Box 1 | "Super donors."

There is growing evidence that FMT therapeutic success depends on the microbial diversity and composition of the stool donor, leading to the concept of "super-donors"-a term suggested to describe donors whose stool is therapeutically significantly more effective when compared to other donors treatment outcomes (134). Currently, there is little but promising clinical evidence for the existence of super-donors, including one randomized clinical trial (56) investigating the efficacy of FMT for inducing clinical remission in patients with Ulcerative Colitis, where out of nine patients treated with FMT who achieved clinical remission, seven patients received stool from the same donor. This finding was seen in an additional randomized control trial by Paramsothy et al. when FMT that contained stool from one donor exhibited a higher remission rate compared with patients treated without the samples from the super-donor.

\section{Sample Handling}

Donated sample handling from collection to administration is an additional process that predisposes to methodological and outcome differences (Figure 3). After their collation samples are generally resuspended and diluted in isotonic fluids, filtered from solids, all the while being in an anaerobic condition. The samples are then either transplanted or stored frozen in a stool bank (Box 2) for later use to provide an on-demand availability. It remains unknown whether a dietary or antibiotic "pre-conditioning" of the donor enhances FMT's efficacy. Likewise, it remains unknown whether freezing compromises sample's quality (137). One remarkable small human study transplanted bacterial-free FMT, by filtering fecal samples prior to their transplantation, to successfully treat $C$. difficile infection, underscoring the importance of fecal metabolites and non-bacterial microbiome in FMT's efficacy, which necessitates further exploration $(138,139)$.

\section{Box 2 | Stool banking.}

Since related FMT donors failed to show any benefit over unrelated donor FMT, healthy donor FMT became more available as unrelated donor FMT was more easily accessible and led to the establishment of stool banks (140). These banks aid treating physicians to initiate treatment instantly when needed, as FMT donors are recruited, evaluated, and screened for infectious disease in advance (141). So far, such banks exit only in several countries worldwide (142).

\section{Mode of Administration}

Additional pending obstacles to broader utilization of FMT are the appropriate doses and route of administration [e.g., oral capsules, gastroduodenoscopy, colonoscopy, or enema; (143-146)]. The gut microbiome composition changes spatially throughout the length of the gastrointestinal tract $(116,147)$. It is generally assumed that the diseaseassociated portion of the gastrointestinal tract is the source of dysbiosis, and therefore should come in contact with donor's fecal material. For instance, trials for FMT in Ulcerative Colitis most often utilize colonoscopies and enemas (148), while trials looking at FMT for cardiometabolic syndrome, known to be affected by incretin secretion from the proximal gastrointestinal tract utilize duodenal infusions $(14,115,121)$. However, it is possible and currently unexplored that combining more than one administration route is superior to a single administration route. In addition, repeated administrations might be needed to enable primary colonization or maintaining it in medical conditions that are chronic in nature $(56,59,149)$. Indeed, an initial administration by colonoscopy followed by two subsequent enemas were successful at inducing remission in Ulcerative Colitis patients (57). These important methodological considerations may greatly impact clinical results of FMT and merit further consideration. 


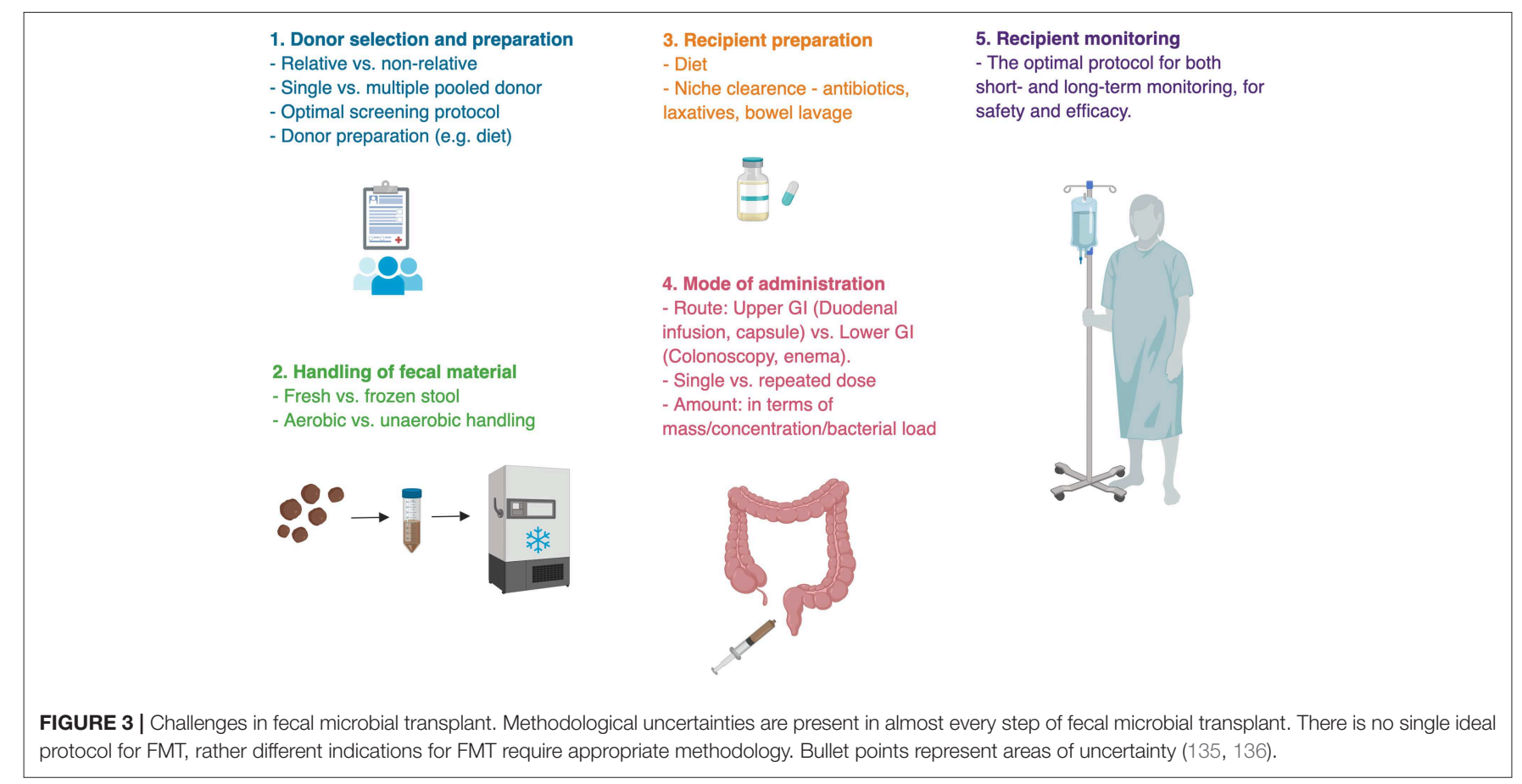

\section{Colonization Resistance}

Many of the pre-clinical FMT models fail to translate into clinical practice $(131,150-154)$ while those that do mainly involve small-scale short-term clinical trials (57, 155-158). One potential caveat leading to FMT failure, which is often under-studied, includes colonization resistance of the recipient's gut to the transplanted ecosystem, which may differ between transplanted individuals. Such resistance has been recently demonstrated toward exogenous probiotics (116) and may involve intrinsic features of the indigenous microbiome, or of the host innate and adaptive immune responses. However, these donor-recipient-specific features may potentially enable to predict colonization success ahead of FMT, thereby suggesting that future personalized FMT optimization and personalized tailoring may be feasible (116).

\section{Adverse Effects}

Although reported to be fairly safe in most clinical trials, FMT is not free of adverse effects, and mild temporary adverse effects are quite common. These include mild diarrhea (reported in up to $94 \%$ of cases in some series), abdominal pain (31\%), abdominal bloating, nausea, headaches, and fatigue (159). Although most patients' complaints resolve within a few hours from treatment administration, some patients suffer from prolonged symptomatology. Some reports linked FMT with IBD worsening (160). A case report described new-onset obesity following FMT from an overweight donor in a previously lean patient treated for C. difficile (161). Furthermore, one study with a fairly long follow up examined whether patients developed new conditions following FMT and found that 5.1\% of patients developed immunologic diseases, including peripheral neuropathy, Sjogren's disease, idiopathic thrombocytopenic purpura, and rheumatoid arthritis (162). Whether these are directly caused by transferred fecal elements or are coincidental findings remain unknown. One patient has died due to aspiration during sedation for FMT via colonoscopy, and another patient died during duodenal infusion of FMT (163).

Additionally, as stool contains thousands of bacterial strains, viruses, fungi, parasites, and a vast array of metabolites, FMT poses a constant risk of microbial transfer to donors that may harmfully impact them. Pathogenic screening of donor samples is often very limited and includes common transmissible pathogens (e.g., Cytomegalovirus, Epstein-Barr virus, Hepatitis A, $B, C$, and E, Norovirus, Rotavirus, Syphilis, Entamoeba histolytica, Strongyloides stercoralis, Giardia lamblia, Cryptosporidium parvum, Blastocystis hominis, Helicobacter pylori, Salmonella, Shigella, Yersinia, E. coli O157:H7, Vancomycin-resistant Enterococcus, methicillin-resistant Staphylococcus aureus, C. difficile, Campylobacter, Vibrio cholera, Listeria monocytogenes), while overlooking unknown transmissible pathogens or commensals that may impact recipient physiology in the short or long-term period (163). Indeed, several cases have emerged in which FMT was suggested to contribute to unrelated diseases in recipients $(161,164,165)$. Albeit unproven, these potentials highlight the non-specific and undefined nature of the transferred microbial configuration. To this end, the use of rationally-defined bacterial consortia (166168) and autologous microbiota transplantation (Box 3) are holding great promise as possible future refinements of FMT toward safer therapeutic options. Consideration and understanding of the scope of adverse effects of FMT are greatly needed, in assessing risk vs. benefit and ensuring a safe and efficacious procedure. 
Box 3 | Autologous FMT.

Although often used as placebo-equivalent in allogeneic-FMT clinical trials, autologous FMT might have a beneficial value in certain clinical situations. Autologous-FMT involves using stool taken from patients at an earlier time point while in a disease-free state or before a critical procedure $(169,170)$. In this context, the recipient serves as his/her own donor. Treating a patient with his own stool taken during a healthier, relatively homeostatic-state, aims at replenishing his original "healthy" microbiota, and by that restoring some aspects of his normal physiologic state. This strategy lacks many of the disadvantages that allogeneic-FMT has such as donor selection, colonization resistance, and unrelated pathogenesis. Interestingly, a single infusion of autologous-FMT was shown to not only rapidly and effectively reconstruct patients' original microbiota composition to its baseline, but also to restore the human epithelial transcriptome throughout the entirety of their gastrointestina tract, following antibiotic perturbations $(171,172)$. Although microbiome parameters and host's global gut gene expression profile were shown to be swiftly reconstituted by autologous-FMT following antibiotics exposure, clinical benefits of this approach merit further studies $(171,173)$. Examples of currently ongoing clinical trials utilizing autologous-FMT include trials testing its efficacy in treating acute graft-vs.-host disease and as prevention of $C$. difficile infection following hematopoietic stem-cell transplantation which is often associated with high risk for $\mathrm{C}$. difficile infection due to exposure to multiple courses of antibiotics.

\section{Cost Effectiveness}

In addition to the therapeutic value of FMT, several costeffectiveness analyses assessed the cost-effectiveness of FMT in recurrent $C$. difficile infection. The first demonstrated a clear advantage to FMT delivered by colonoscopy as compared to other treatment strategies in patients with recurrent $C$. difficile infection (174), but only included a single FMT infusion. The second demonstrated a cost-effectiveness advantage of FMT in the third $C$. difficile colitis recurrence (175). The third compared oral vancomycin to two methods of FMT deliverance (nasoduodenal and colonoscopy) of FMT, showing that both methods are superior to oral antibiotics (176). Other studies that analyzed the cost-effectiveness of FMT for the treatment of initial C. difficile infection, failed to demonstrate that FMT has an advantage over oral metronidazole $(177,178)$.

\section{Cardiometabolic Syndrome-Specific Limitations in FMT Utilization}

On top of the above inherent limitations and challenges of FMT in general (Figure 3), there are a few barriers to the utilization of FMT in treating cardiometabolic syndrome. First, despite robust preclinical evidence, human evidence to support FMT in cardiometabolic syndrome is fairly scarce and weak. All three clinical trials were carried out by the same group of researchers and demonstrated modest, transient effect in a limited selection of patients, with considerable variability in response to treatment. Second, different professional organizations define cardiometabolic syndrome using different sets of criteria, with no single universal set of diagnostic criteria accepted by all (1, 179, 180). Moreover, all definitions require patients to only partially fulfill the list of criteria, therefore patients have different metabolic aberrations of variable severity, resulting in a very heterogeneous patients' population. Last, cardiometabolic syndrome is a chronic disorder that may necessitate multiple fecal transfers, in avoiding a transient effect. This repeated regimen is expected to lower its cost-effectiveness and patients' compliance.

\section{PROSPECTS AND CONCLUSIONS}

While FMT has emerged as an important therapy for defined indications such as $C$. difficile colitis, it faces major barriers and challenges in being adopted as an intervention in cardiometabolic disease. With that said, a variety of challenges may be tackled in optimizing FMT for chronic metabolic indications. Issues such as donor selection, sample handling, predicting recipient compatibility to a given donor microbiome, and standardization of therapeutic FMT protocol may result in improved outcomes of these interventions and in higher reproducibility between studies. Moreover, a better understanding of causative vs. "passenger" bacteria, and of the contribution of non-bacterial components of the gut microbiome such as the virome and fungome may enable to formulate a defined microbial signature that would optimize efficacy while improving the safety of the procedure and its long-term effects on the recipients.

Utilizing autologous-FMT as means of "rejuvenating" a person's microbiome toward a pre-disease configuration may offer an attractive opportunity to optimize colonization, ensure safety, and avoid inter-individual incompatibilities. It may prove clinically useful in treating some complications of dysbiosisinducing elective medical interventions such as chemotherapy (181), hematopoietic stem-cell transplantation (171, 182), surgery (183) or exposure to wide-spectrum antibiotics $(172,184$, 185). In the context of cardiometabolic syndrome it may help to reverse microbiome contributions toward obesity, TIIDM, and NAFLD while resetting the host toward a healthier metabolic state (40).

While a deeper mechanistic understanding of discrete commensal functions and their modulatory activities on bioactive metabolites may enable the development of more precise microbiome-associated treatments, the advantage of patient supplementation with an intact bacterial ecosystem with its intricate and cross-supportive interaction networks may enhance the clinical efficacy of such treatment over monoinoculation with a commensal or its metabolic product. However, adverse effects associated with the unknown components of the transferred ecosystem into a foreign host need to be extensively studied and taken into consideration when assessing the risk vs. benefit of FMT for metabolic and other indications.

\section{AUTHOR CONTRIBUTIONS}

$\mathrm{AL}$ and $\mathrm{NH}$ contributed equally to literature search, integration of data, and the writing of this review. EE supervised data gathering and integration and headed the writing of the review. 


\section{ACKNOWLEDGMENTS}

We thank the members of the Elinav lab for discussions and apologize to authors whose work was not included due to space constraints. EE is supported by Y. and R. Ungar, the Abisch Frenkel Foundation for the Promotion of Life Sciences, the Gurwin Family Fund for Scientific Research, the Leona M. and Harry B. Helmsley Charitable Trust, the Crown Endowment Fund for Immunological Research, the estate of J. Gitlitz, the estate of L. Hershkovich, the Benoziyo Endowment Fund for the Advancement of Science, the Adelis Foundation, J. L. and V. Schwartz, A. and G. Markovitz, A.

\section{REFERENCES}

1. Grundy SM, Cleeman JI, Daniels SR, Donato KA, Eckel RH, Franklin $\mathrm{BA}$, et al. Diagnosis and management of the metabolic syndrome: an American Heart Association/National Heart, Lung, and Blood Institute Scientific Statement. Circulation. (2005) 112:2735-52. doi: 10.1161/CIRCULATIONAHA.105.169404

2. Ford ES, Giles WH, Dietz WH. Prevalence of the metabolic syndrome among US adults: findings from the third National Health and Nutrition Examination Survey. JAMA. (2002) 287:356-9. doi: $10.1001 /$ jama.287.3.356

3. Ford ES, Giles WH, Mokdad AH. Increasing prevalence of the metabolic syndrome among U.S. Adults. Diabetes Care. (2004) 27:2444-9. doi: $10.2337 /$ diacare.27.10.2444

4. Wilson PW, D'Agostino RB, Parise H, Sullivan L, Meigs JB. Metabolic syndrome as a precursor of cardiovascular disease and type 2 diabetes mellitus. Circulation. (2005) 112:3066-72. doi: 10.1161/CIRCULATIONAHA.105.539528

5. Ford ES. Risks for all-cause mortality, cardiovascular disease, and diabetes associated with the metabolic syndrome: a summary of the evidence. Diabetes Care. (2005) 28:1769-78. doi: 10.2337/diacare.28. 7.1769

6. Galassi A, Reynolds K, He J. Metabolic syndrome and risk of cardiovascular disease: a meta-analysis. Am J Med. (2006) 119:812-9. doi: 10.1016/j.amjmed.2006.02.031

7. Gami AS, Witt BJ, Howard DE, Erwin PJ, Gami LA, Somers VK, et al. Metabolic syndrome and risk of incident cardiovascular events and death: a systematic review and meta-analysis of longitudinal studies. J Am Coll Cardiol. (2007) 49:403-14. doi: 10.1016/j.jacc.2006.09.032

8. Ford ES, Li C, Sattar N. Metabolic syndrome and incident diabetes: current state of the evidence. Diabetes Care. (2008) 31:1898-904. doi: $10.2337 / \mathrm{dc} 08-0423$

9. Koh KK, Han $\mathrm{SH}$, Quon MJ. Inflammatory markers and the metabolic syndrome: insights from therapeutic interventions. J Am Coll Cardiol. (2005) 46:1978-85. doi: 10.1016/j.jacc.2005.06.082

10. Ridker PM, Buring JE, Cook NR, Rifai N. C-reactive protein, the metabolic syndrome, and risk of incident cardiovascular events: an 8-year follow-up of 14719 initially healthy American women. Circulation. (2003) 107:391-7. doi: 10.1161/01.CIR.0000055014.62083.05

11. Festa A, D'Agostino R Jr., Howard G, Mykkanen L, Tracy RP, Haffner SM. Chronic subclinical inflammation as part of the insulin resistance syndrome: the Insulin Resistance Atherosclerosis Study (IRAS). Circulation. (2000) 102:42-7. doi: 10.1161/01.CIR.102.1.42

12. Festa A, D'Agostino R Jr., Tracy RP, Haffner SM, Insulin Resistance Atherosclerosis S. Elevated levels of acute-phase proteins and plasminogen activator inhibitor-1 predict the development of type 2 diabetes: the insulin resistance atherosclerosis study. Diabetes. (2002) 51:1131-7. doi: $10.2337 /$ diabetes.51.4.1131

13. Hu FB, Meigs JB, Li TY, Rifai N, Manson JE. Inflammatory markers and risk of developing type 2 diabetes in women. Diabetes. (2004) 53:693-700. doi: $10.2337 /$ diabetes.53.3.693 and C. Adelson, the French National Center for Scientific Research (CNRS), D. L. Schwarz, the V. R. Schwartz Research Fellow Chair, L. Steinberg, J. N. Halpern, A. Edelheit, grants funded by the European Research Council, a Marie Curie Integration grant, the German-Israeli Foundation for Scientific Research and Development, the Israel Science Foundation, the Minerva Foundation, the Rising Tide Foundation, the Helmholtz Foundation, and the European Foundation for the Study of Diabetes. EE is a senior fellow of the Canadian Institute of Advanced Research (CIFAR) and an international scholar of the Bill and Melinda Gates Foundation and Howard Hughes Medical Institute (HHMI).

14. Vrieze A, Van Nood E, Holleman F, Salojarvi J, Kootte RS, Bartelsman JF, et al. Transfer of intestinal microbiota from lean donors increases insulin sensitivity in individuals with metabolic syndrome. Gastroenterology. (2012) 143:913-6 e7. doi: 10.1053/j.gastro.2012.06.031

15. Xiao S, Fei N, Pang X, Shen J, Wang L, Zhang B, et al. A gut microbiotatargeted dietary intervention for amelioration of chronic inflammation underlying metabolic syndrome. FEMS Microbiol Ecol. (2014) 87:357-67. doi: $10.1111 / 1574-6941.12228$

16. Nelson JR. Dantrolene sodium (Dantrium-Eaton) for relief of spasticity. West J Med. (1975) 123:131.

17. Cani PD. Human gut microbiome: hopes, threats and promises. Gut. (2018) 67:1716-25. doi: 10.1136/gutjnl-2018-316723

18. Ximenez C, Torres J. Development of microbiota in infants and its role in maturation of gut mucosa and immune system. Arch Med Res. (2017) 48:666-80. doi: 10.1016/j.arcmed.2017.11.007

19. Milani C, Duranti S, Bottacini F, Casey E, Turroni F, Mahony J, et al. The first microbial colonizers of the human gut: composition, activities, and health implications of the infant gut microbiota. Microbiol Mol Biol Rev. (2017) 81:4. doi: 10.1128/MMBR.00036-17

20. Aleksandrova K, Romero-Mosquera B, Hernandez V. Diet, gut microbiome and epigenetics: emerging links with inflammatory bowel diseases and prospects for management and prevention. Nutrients. (2017) 9:9. doi: 10.3390/nu9090962

21. Halfvarson J, Brislawn CJ, Lamendella R, Vazquez-Baeza Y, Walters WA, Bramer LM, et al. Dynamics of the human gut microbiome in inflammatory bowel disease. Nat Microbiol. (2017) 2:17004. doi: 10.1038/nmicrobiol.2017.4

22. Kennedy PJ, Cryan JF, Dinan TG, Clarke G. Irritable bowel syndrome: a microbiome-gut-brain axis disorder? World J Gastroenterol. (2014) 20:14105-25. doi: 10.3748/wjg.v20.i39.14105

23. Downs IA, Aroniadis OC, Kelly L, Brandt LJ. Postinfection irritable bowel syndrome: the links between gastroenteritis, inflammation, the microbiome, and functional disease. J Clin Gastroenterol. (2017) 51:869-77. doi: 10.1097/MCG.0000000000000924

24. Tilg $\mathrm{H}$, Adolph TE, Gerner RR, Moschen AR. The intestinal microbiota in colorectal cancer. Cancer Cell. (2018) 33:954-64. doi: 10.1016/j.ccell.2018.03.004

25. Weng MT, Chiu YT, Wei PY, Chiang CW, Fang HL, Wei SC. Microbiota and gastrointestinal cancer. J Formosan Med Assoc. (2019) 2019:002. doi: 10.1016/j.jfma.2019.01.002

26. Geller LT, Barzily-Rokni M, Danino T, Jonas OH, Shental N, Nejman D, et al. Potential role of intratumor bacteria in mediating tumor resistance to the chemotherapeutic drug gemcitabine. Science. (2017) 357:1156-60. doi: 10.1126/science.aah5043

27. Shin NR, Lee JC, Lee HY, Kim MS, Whon TW, Lee MS, et al. An increase in the Akkermansia spp. population induced by metformin treatment improves glucose homeostasis in diet-induced obese mice. Gut. (2014) 63:727-35. doi: 10.1136/gutjnl-2012-303839

28. Koren O, Spor A, Felin J, Fak F, Stombaugh J, Tremaroli V, et al. Human oral, gut, and plaque microbiota in patients with atherosclerosis. Proc Natl Acad Sci USA. (2011) 108(Suppl 1):4592-8. doi: 10.1073/pnas.1011 383107 
29. Felice VD, O'Mahony SM. The microbiome and disorders of the central nervous system. Pharmacol Biochem Behav. (2017) 160:1-13. doi: 10.1016/j.pbb.2017.06.016

30. Rosenfeld CS. Microbiome disturbances and autism spectrum disorders. Drug Metabol Dispos Biol Fate Chem. (2015) 43:1557-71. doi: $10.1124 / \mathrm{dmd} .115 .063826$

31. Dickerson F, Severance E, Yolken R. The microbiome, immunity, and schizophrenia and bipolar disorder. Brain Behav Immun. (2017) 62:46-52. doi: 10.1016/j.bbi.2016.12.010

32. Cenit MC, Sanz Y, Codoner-Franch P. Influence of gut microbiota on neuropsychiatric disorders. World J Gastroenterol. (2017) 23:5486-98. doi: 10.3748/wjg.v23.i30.5486

33. Zhao Y, Wu J, Li JV, Zhou NY, Tang H, Wang Y. Gut microbiota composition modifies fecal metabolic profiles in mice. J Proteome Res. (2013) 12:2987-99. doi: $10.1021 /$ pr400263n

34. Lin H, An Y, Hao F, Wang Y, Tang H. Correlations of fecal metabonomic and microbiomic changes induced by high-fat diet in the pre-obesity state. Sci Rep. (2016) 6:21618. doi: 10.1038/srep21618

35. David LA, Maurice CF, Carmody RN, Gootenberg DB, Button JE, Wolfe $\mathrm{BE}$, et al. Diet rapidly and reproducibly alters the human gut microbiome. Nature. (2014) 505:559-63. doi: 10.1038/nature12820

36. Zeevi D, Korem T, Zmora N, Israeli D, Rothschild D, Weinberger A, et al. Personalized nutrition by prediction of glycemic responses. Cell. (2015) 163:1079-94. doi: 10.1016/j.cell.2015.11.001

37. Walker AW, Ince J, Duncan SH, Webster LM, Holtrop G, Ze X, et al. Dominant and diet-responsive groups of bacteria within the human colonic microbiota. ISME J. (2011) 5:220-30. doi: 10.1038/ismej. 2010.118

38. Shanahan F, Quigley EM. Manipulation of the microbiota for treatment of IBS and IBD-challenges and controversies. Gastroenterology. (2014) 146:1554-63. doi: 10.1053/j.gastro.2014.01.050

39. Freedman SB, Williamson-Urquhart S, Farion KJ, Gouin S, Willan AR, Poonai N, et al. Multicenter trial of a combination probiotic for children with gastroenteritis. N Engl J Med. (2018) 379:2015-26. doi: 10.1056/NEJMoa1802597

40. Thaiss CA, Itav S, Rothschild D, Meijer MT, Levy M, Moresi C, et al. Persistent microbiome alterations modulate the rate of post-dieting weight regain. Nature. (2016) 540:544-51. doi: 10.1038/nature20796

41. Chen H, Nwe PK, Yang Y, Rosen CE, Bielecka AA, Kuchroo M, et al. A forward chemical genetic screen reveals gut microbiota metabolites that modulate host physiology. Cell. (2019) 2019:36. doi: 10.1016/j.cell.2019.03.036

42. Voelker R. FDA approves bacteriophage trial. JAMA. (2019) 321:638. doi: 10.1001/jama.2019.0510

43. Khalifa L, Brosh Y, Gelman D, Coppenhagen-Glazer S, Beyth S, PoradosuCohen R, et al. Targeting Enterococcus faecalis biofilms with phage therapy. Appl Environ Microbiol. (2015) 81:2696-705. doi: 10.1128/AEM. 00096-15

44. Stern A, Mick E, Tirosh I, Sagy O, Sorek R. CRISPR targeting reveals a reservoir of common phages associated with the human gut microbiome. Genome Res. (2012) 22:1985-94. doi: 10.1101/gr.138297.112

45. Gelman D, Beyth S, Lerer V, Adler K, Poradosu-Cohen R, CoppenhagenGlazer S, et al. Combined bacteriophages and antibiotics as an efficient therapy against VRE Enterococcus faecalis in a mouse model. Res Microbiol. (2018) 169:531-9. doi: 10.1016/j.resmic.2018.04.008

46. Kortright KE, Chan BK, Koff JL, Turner PE. Phage therapy: a renewed approach to combat antibiotic-resistant bacteria. Cell Host Microbe. (2019) 25:219-32. doi: 10.1016/j.chom.2019.01.014

47. Doron S, Melamed S, Ofir G, Leavitt A, Lopatina A, Keren M, et al. Systematic discovery of antiphage defense systems in the microbial pangenome. Science. (2018) 359:6379. doi: 10.1126/science.aar4120

48. Barr JJ. A bacteriophages journey through the human body. Immunol Rev. (2017) 279:106-22. doi: 10.1111/imr. 12565

49. Oh JH, Alexander LM, Pan M, Schueler KL, Keller MP, Attie AD, et al. Dietary fructose and microbiota-derived short-chain fatty acids promote bacteriophage production in the gut symbiont Lactobacillus reuteri. Cell Host Microbe. (2019) 25:273-84 e6. doi: 10.1016/j.chom.2018.11.016
50. Thaiss CA, Levy M, Grosheva I, Zheng D, Soffer E, Blacher E, et al. Hyperglycemia drives intestinal barrier dysfunction and risk for enteric infection. Science. (2018) 359:1376-83. doi: 10.1126/science.aar3318

51. Evrensel A, Ceylan ME. Fecal microbiota transplantation and its usage in neuropsychiatric disorders. Clin Psychopharmacol Neurosci. (2016) 14:231-7. doi: 10.9758/cpn.2016.14.3.231

52. Eiseman B, Silen W, Bascom GS, Kauvar AJ. Fecal enema as an adjunct in the treatment of pseudomembranous enterocolitis. Surgery. (1958) 44:854-9.

53. Freeman J, Bauer MP, Baines SD, Corver J, Fawley WN, Goorhuis B, et al. The changing epidemiology of Clostridium difficile infections. Clin Microbiol Rev. (2010) 23:529-49. doi: 10.1128/CMR.00082-09

54. Kelly CP, LaMont JT. Clostridium difficile-more difficult than ever. N Engl J Med. (2008) 359:1932-40. doi: 10.1056/NEJMra0707500

55. van Nood E, Vrieze A, Nieuwdorp M, Fuentes S, Zoetendal EG, de Vos WM, et al. Duodenal infusion of donor feces for recurrent Clostridium difficile. $N$ Engl J Med. (2013) 368:407-15. doi: 10.1056/NEJMoa1205037

56. Moayyedi P, Surette MG, Kim PT, Libertucci J, Wolfe M, Onischi C, et al. Fecal microbiota transplantation induces remission in patients with active ulcerative colitis in a randomized controlled trial. Gastroenterology. (2015) 149:102-9 e6. doi: 10.1053/j.gastro.2015.04.001

57. Costello SP, Hughes PA, Waters O, Bryant RV, Vincent AD, Blatchford P, et al. Effect of fecal microbiota transplantation on 8-week remission in patients with ulcerative colitis: a randomized clinical trial. JAMA. (2019) 321:156-64. doi: 10.1001/jama.2018.20046

58. Narula N, Kassam Z, Yuan Y, Colombel JF, Ponsioen C, Reinisch W, et al. Systematic review and meta-analysis: fecal microbiota transplantation for treatment of active ulcerative colitis. Inflamm Bowel Dis. (2017) 23:1702-9. doi: 10.1097/MIB.0000000000001228

59. Rossen NG, Fuentes S, van der Spek MJ, Tijssen JG, Hartman JH, Duflou A, et al. Findings from a randomized controlled trial of fecal transplantation for patients with ulcerative colitis. Gastroenterology. (2015) 149:110-8 e4. doi: 10.1053/j.gastro.2015.03.045

60. Cui B, Feng Q, Wang H, Wang M, Peng Z, Li P, et al. Fecal microbiota transplantation through mid-gut for refractory Crohn's disease: safety, feasibility, and efficacy trial results. J Gastroenterol Hepatol. (2015) 30:51-8. doi: 10.1111/jgh.12727

61. Vermeire S, Joossens M, Verbeke K, Wang J, Machiels K, Sabino J, et al. Donor species richness determines faecal microbiota transplantation success in inflammatory bowel disease. J Crohn Colitis. (2016) 10:387-94. doi: 10.1093/ecco-jcc/jjv203

62. Nakamoto N, Sasaki N, Aoki R, Miyamoto K, Suda W, Teratani $\mathrm{T}$, et al. Gut pathobionts underlie intestinal barrier dysfunction and liver $\mathrm{T}$ helper 17 cell immune response in primary sclerosing cholangitis. Nat Microbiol. (2019) 4:492-503. doi: 10.1038/s41564-01 8-0333-1

63. Allegretti JR, Kassam Z, Carrellas M, Mullish BH, Marchesi JR, Pechlivanis A, et al. Fecal microbiota transplantation in patients with primary sclerosing cholangitis: a pilot clinical trial. Am J Gastroenterol. (2019) 2019:115. doi: 10.14309/ajg.0000000000000115

64. Johnsen PH, Hilpusch F, Cavanagh JP, Leikanger IS, Kolstad C, Valle PC, et al. Faecal microbiota transplantation versus placebo for moderate-to-severe irritable bowel syndrome: a double-blind, randomised, placebo-controlled, parallel-group, single-centre trial. Lancet Gastroenterol Hepatol. (2018) 3:1724. doi: 10.1016/S2468-1253(17)30338-2

65. Halkjaer SI, Christensen AH, Lo BZS, Browne PD, Gunther S, Hansen LH, et al. Faecal microbiota transplantation alters gut microbiota in patients with irritable bowel syndrome: results from a randomised, double-blind placebocontrolled study. Gut. (2018) 67:2107-15. doi: 10.1136/gutjnl-2018-3 16434

66. Turnbaugh PJ, Ley RE, Mahowald MA, Magrini V, Mardis ER, Gordon JI. An obesity-associated gut microbiome with increased capacity for energy harvest. Nature. (2006) 444:1027-31. doi: 10.1038/nature05414

67. Ridaura VK, Faith JJ, Rey FE, Cheng J, Duncan AE, Kau AL, et al. Gut microbiota from twins discordant for obesity modulate metabolism in mice. Science. (2013) 341:1241214. doi: 10.1126/science.12 41214

68. Tremaroli V, Karlsson F, Werling M, Ståhlman M, Kovatcheva-Datchary $\mathrm{P}$, Olbers $\mathrm{T}$, et al. Roux-en-Y gastric bypass and vertical banded 
gastroplasty induce long-term changes on the human gut microbiome contributing to fat mass regulation. Cell Metab. (2015) 22:228-38. doi: 10.1016/j.cmet.2015.07.009

69. Reijnders D, Goossens GH, Hermes GD, Neis EP, van der Beek CM, Most J, et al. Effects of gut microbiota manipulation by antibiotics on host metabolism in obese humans: a randomized double-blind placebocontrolled trial. Cell Metab. (2016) 24:63-74. doi: 10.1016/j.cmet.2016.06.016

70. Vrieze A, Out C, Fuentes S, Jonker L, Reuling I, Kootte RS, et al. Impact of oral vancomycin on gut microbiota, bile acid metabolism, and insulin sensitivity. J Hepatol. (2014) 60:824-31. doi: 10.1016/j.jhep.2013.11.034

71. Li J, Zhao F, Wang Y, Chen J, Tao J, Tian G, et al. Gut microbiota dysbiosis contributes to the development of hypertension. Microbiome. (2017) 5:14. doi: 10.1186/s40168-016-0222-x

72. Vijay-Kumar M, Aitken JD, Carvalho FA, Cullender TC, Mwangi S, Srinivasan S, et al. Metabolic syndrome and altered gut microbiota in mice lacking Toll-like receptor 5. Science. (2010) 328:228-31. doi: $10.1126 /$ science. 1179721

73. Backhed F, Ding H, Wang T, Hooper LV, Koh GY, Nagy A, et al. The gut microbiota as an environmental factor that regulates fat storage. Proc Natl Acad Sci USA. (2004) 101:15718-23. doi: 10.1073/pnas.0407076101

74. Turnbaugh PJ, Backhed F, Fulton L, Gordon JI. Diet-induced obesity is linked to marked but reversible alterations in the mouse distal gut microbiome. Cell Host Microbe. (2008) 3:213-23. doi: 10.1016/j.chom.2008.02.015

75. Backhed F, Manchester JK, Semenkovich CF, Gordon JI. Mechanisms underlying the resistance to diet-induced obesity in germ-free mice. Proc Natl Acad Sci USA. (2007) 104:979-84. doi: 10.1073/pnas.0605374104

76. Rabot S, Membrez M, Bruneau A, Gerard P, Harach T, Moser M, et al. Germfree C57BL/6J mice are resistant to high-fat-diet-induced insulin resistance and have altered cholesterol metabolism. FASEB J. (2010) 24:4948-59. doi: 10.1096/fj.10-164921

77. Caesar R, Tremaroli V, Kovatcheva-Datchary P, Cani PD, Backhed F. Crosstalk between gut microbiota and dietary lipids aggravates WAT inflammation through TLR signaling. Cell Metab. (2015) 22:658-68. doi: 10.1016/j.cmet.2015.07.026

78. Kubeck R, Bonet-Ripoll C, Hoffmann C, Walker A, Muller VM, Schuppel VL, et al. Dietary fat and gut microbiota interactions determine diet-induced obesity in mice. Mol Metab. (2016) 5:1162-74. doi: 10.1016/j.molmet.2016.10.001

79. Watanabe K, Igarashi M, Li X, Nakatani A, Miyamoto J, Inaba Y, et al. Dietary soybean protein ameliorates high-fat diet-induced obesity by modifying the gut microbiota-dependent biotransformation of bile acids. PLoS ONE. (2018) 13:e0202083. doi: 10.1371/journal.pone.0202083

80. Just S, Mondot S, Ecker J, Wegner K, Rath E, Gau L, et al. The gut microbiota drives the impact of bile acids and fat source in diet on mouse metabolism. Microbiome. (2018) 6:134. doi: 10.1186/s40168-018-0510-8

81. Zmora N, Suez J, Elinav E. You are what you eat: diet, health and the gut microbiota. Nat Rev Gastroenterol Hepatol. (2019) 16:35-56. doi: 10.1038/s41575-018-0061-2

82. Fleissner CK, Huebel N, Abd El-Bary MM, Loh G, Klaus S, Blaut M. Absence of intestinal microbiota does not protect mice from diet-induced obesity. $\mathrm{Br}$ J Nutr. (2010) 104:919-29. doi: 10.1017/S0007114510001303

83. Miyamoto J, Watanabe K, Taira S, Kasubuchi M, Li X, Irie J, et al. Barley betaglucan improves metabolic condition via short-chain fatty acids produced by gut microbial fermentation in high fat diet fed mice. PLoS ONE. (2018) 13:e0196579. doi: 10.1371/journal.pone.0196579

84. Rabot S, Membrez M, Blancher F, Berger B, Moine D, Krause L, et al. High fat diet drives obesity regardless the composition of gut microbiota in mice. Sci Rep. (2016) 6:32484. doi: 10.1038/srep32484

85. Zou J, Chassaing B, Singh V, Pellizzon M, Ricci M, Fythe MD, et al. Fiber-mediated nourishment of gut microbiota protects against diet-induced obesity by restoring IL-22-mediated colonic health. Cell Host Microbe. (2018) 23:41-53 e4. doi: 10.1016/j.chom.2017.11.003

86. Kim TT, Parajuli N, Sung MM, Bairwa SC, Levasseur J, Soltys CM, et al. Fecal transplant from resveratrol-fed donors improves glycaemia and cardiovascular features of the metabolic syndrome in mice. Am J Physiol Endocrinol Metab. (2018) 315:E511-9. doi: 10.1152/ajpendo.00471.2017
87. Koren O, Goodrich JK, Cullender TC, Spor A, Laitinen K, Backhed HK, et al. Host remodeling of the gut microbiome and metabolic changes during pregnancy. Cell. (2012) 150:470-80. doi: 10.1016/j.cell.2012.07.008

88. Suez J, Korem T, Zeevi D, Zilberman-Schapira G, Thaiss CA, Maza O, et al. Artificial sweeteners induce glucose intolerance by altering the gut microbiota. Nature. (2014) 514:181-6. doi: 10.1038/nature13793

89. Wu H, Esteve E, Tremaroli V, Khan MT, Caesar R, Manneras-Holm L, et al. Metformin alters the gut microbiome of individuals with treatment-naive type 2 diabetes, contributing to the therapeutic effects of the drug. Nat Med. (2017) 23:850-8. doi: 10.1038/nm.4345

90. Sun L, Xie C, Wang G, Wu Y, Wu Q, Wang X, et al. Gut microbiota and intestinal FXR mediate the clinical benefits of metformin. Nat Med. (2018) 24:1919-29. doi: 10.1038/s41591-018-0222-4

91. Marques FZ, Mackay CR, Kaye DM. Beyond gut feelings: how the gut microbiota regulates blood pressure. Nat Rev Cardiol. (2018) 15:20-32. doi: 10.1038/nrcardio.2017.120

92. Robciuc MR, Skrobuk P, Anisimov A, Olkkonen VM, Alitalo K, Eckel RH, et al. Angiopoietin-like 4 mediates PPAR delta effect on lipoprotein lipase-dependent fatty acid uptake but not on beta-oxidation in myotubes. PLoS ONE. (2012) 7:e46212. doi: 10.1371/journal.pone.0 046212

93. Shapiro H, Thaiss CA, Levy M, Elinav E. The cross talk between microbiota and the immune system: metabolites take center stage. Curr Opin Immunol. (2014) 30:54-62. doi: 10.1016/j.coi.2014.07.003

94. Shapiro H, Kolodziejczyk AA, Halstuch D, Elinav E. Bile acids in glucose metabolism in health and disease. J Exp Med. (2018) 215:383-96. doi: $10.1084 /$ jem. 20171965

95. Abbasi J. Unveiling the "magic" of diabetes remission after weight-loss surgery. JAMA. (2017) 317:571-4. doi: 10.1001/jama.2017.0020

96. El Khoury L, Chouillard E, Chahine E, Saikaly E, Debs T, Kassir R. Metabolic surgery and diabesity: a systematic review. Obes Surg. (2018) 28:2069-77. doi: 10.1007/s11695-018-3252-6

97. Kaplan LM. What bariatric surgery can teach us about endoluminal treatment of obesity and metabolic disorders. Gastrointest Endosc Clin N Am. (2017) 27:213-31. doi: 10.1016/j.giec.2017.01.004

98. Aron-Wisnewsky J, Dore J, Clement K. The importance of the gut microbiota after bariatric surgery. Nat Rev Gastroenterol Hepatol. (2012) 9:590-8. doi: 10.1038/nrgastro.2012.161

99. Zhang H, DiBaise JK, Zuccolo A, Kudrna D, Braidotti M, Yu Y, et al. Human gut microbiota in obesity and after gastric bypass. Proc Natl Acad Sci USA. (2009) 106:2365-70. doi: 10.1073/pnas.0812600106

100. Arora T, Seyfried F, Docherty NG, Tremaroli V, le Roux CW, Perkins R, et al. Diabetes-associated microbiota in fa/fa rats is modified by Roux-en-Y gastric bypass. ISME J. (2017) 11:2035-46. doi: 10.1038/ismej.2017.70

101. Magouliotis DE, Tasiopoulou VS, Sioka E, Chatedaki C, Zacharoulis D. Impact of bariatric surgery on metabolic and gut microbiota profile: a systematic review and meta-analysis. Obes Surg. (2017) 27:1345-57. doi: 10.1007/s11695-017-2595-8

102. Murphy R, Tsai P, Jullig M, Liu A, Plank L, Booth M. Differential changes in gut microbiota after gastric bypass and sleeve gastrectomy bariatric surgery vary according to diabetes remission. Obes Surg. (2017) 27:917-25. doi: 10.1007/s11695-016-2399-2

103. Bruinsma BG, Uygun K, Yarmush ML, Saeidi N. Surgical models of Roux-en$\mathrm{Y}$ gastric bypass surgery and sleeve gastrectomy in rats and mice. Nat Protoc. (2015) 10:495-507. doi: 10.1038/nprot.2015.027

104. Liou AP, Paziuk M, Luevano JM Jr., Machineni S, Turnbaugh PJ, Kaplan LM. Conserved shifts in the gut microbiota due to gastric bypass reduce host weight and adiposity. Sci Transl Med. (2013) 5:178ra41. doi: $10.1126 /$ scitranslmed.3005687

105. Tims S, Derom C, Jonkers DM, Vlietinck R, Saris WH, Kleerebezem M, et al. Microbiota conservation and BMI signatures in adult monozygotic twins. ISME J. (2013) 7:707-17. doi: 10.1038/ismej.2012.146

106. Smith MI, Yatsunenko T, Manary MJ, Trehan I, Mkakosya R, Cheng J, et al. Gut microbiomes of Malawian twin pairs discordant for kwashiorkor. Science. (2013) 339:548-54. doi: 10.1126/science.1 229000 
107. Goodrich JK, Waters JL, Poole AC, Sutter JL, Koren O, Blekhman R, et al. Human genetics shape the gut microbiome. Cell. (2014) 159:789-99. doi: 10.1016/j.cell.2014.09.053

108. Foley KP, Zlitni S, Denou E, Duggan BM, Chan RW, Stearns JC, et al. Long term but not short term exposure to obesity related microbiota promotes host insulin resistance. Nat Commun. (2018) 9:4681. doi: 10.1038/s41467-018-07146-5

109. Di Luccia B, Crescenzo R, Mazzoli A, Cigliano L, Venditti P, Walser JC, et al. Rescue of fructose-induced metabolic syndrome by antibiotics or faecal transplantation in a rat model of obesity. PLoS ONE. (2015) 10:e0134893. doi: 10.1371/journal.pone.0134893

110. Baur JA, Pearson KJ, Price NL, Jamieson HA, Lerin C, Kalra A, et al. Resveratrol improves health and survival of mice on a high-calorie diet. Nature. (2006) 444:337-42. doi: 10.1038/nature05354

111. Dolinsky VW, Chan AY, Robillard Frayne I, Light PE, Des Rosiers C, Dyck JR. Resveratrol prevents the prohypertrophic effects of oxidative stress on LKB1. Circulation. (2009) 119:1643-52. doi: 10.1161/CIRCULATIONAHA.108.787440

112. Sung MM, Kim TT, Denou E, Soltys CM, Hamza SM, Byrne NJ, et al. Improved glucose homeostasis in obese mice treated with resveratrol is associated with alterations in the gut microbiome. Diabetes. (2017) 66:418-25. doi: 10.2337/db16-0680

113. Karlsson FH, Tremaroli V, Nookaew I, Bergstrom G, Behre CJ, Fagerberg B, et al. Gut metagenome in European women with normal, impaired and diabetic glucose control. Nature. (2013) 498:99-103. doi: 10.1038/nature12198

114. Qin J, Li Y, Cai Z, Li S, Zhu J, Zhang F, et al. A metagenome-wide association study of gut microbiota in type 2 diabetes. Nature. (2012) 490:55-60. doi: $10.1038 /$ nature 11450

115. Kootte RS, Levin E, Salojarvi J, Smits LP, Hartstra AV, Udayappan SD, et al. Improvement of insulin sensitivity after lean donor feces in metabolic syndrome is driven by baseline intestinal microbiota composition. Cell Metab. (2017) 26:611-9 e6. doi: 10.1016/j.cmet.2017.09.008

116. Zmora N, Zilberman-Schapira G, Suez J, Mor U, Dori-Bachash M, Bashiardes $S$, et al. Personalized gut mucosal colonization resistance to empiric probiotics is associated with unique host and microbiome features. Cell. (2018) 174:1388-405 e21. doi: 10.1016/j.cell.2018.08.041

117. Li SS, Zhu A, Benes V, Costea PI, Hercog R, Hildebrand F, et al. Durable coexistence of donor and recipient strains after fecal microbiota transplantation. Science. (2016) 352:586-9. doi: 10.1126/science.a ad8852

118. Tang WH, Wang Z, Levison BS, Koeth RA, Britt EB, Fu X, et al. Intestinal microbial metabolism of phosphatidylcholine and cardiovascular risk. $N$ Engl J Med. (2013) 368:1575-84. doi: 10.1056/NEJMoal 109400

119. Koeth RA, Wang Z, Levison BS, Buffa JA, Org E, Sheehy BT, et al. Intestinal microbiota metabolism of L-carnitine, a nutrient in red meat, promotes atherosclerosis. Nat Med. (2013) 19:576-85. doi: 10.1038/n m.3145

120. Wang Z, Klipfell E, Bennett BJ, Koeth R, Levison BS, Dugar $B$, et al. Gut flora metabolism of phosphatidylcholine promotes cardiovascular disease. Nature. (2011) 472:57-63. doi: 10.1038/nature 09922

121. Smits LP, Kootte RS, Levin E, Prodan A, Fuentes S, Zoetendal EG, et al. Effect of vegan fecal microbiota transplantation on carnitine- and cholinederived trimethylamine-N-oxide production and vascular inflammation in patients with metabolic syndrome. J Am Heart Assoc. (2018) 7:7. doi: 10.1161/JAHA.117.008342

122. Craven LJ, Nair Parvathy S, Tat-Ko J, Burton JP, Silverman MS. Extended screening costs associated with selecting donors for fecal microbiota transplantation for treatment of metabolic syndrome-associated diseases. Open Forum Infect Dis. (2017) 4:ofx243. doi: 10.1093/ofid/o $\mathrm{fx} 243$

123. Woodworth MH, Carpentieri C, Sitchenko KL, Kraft CS. Challenges in fecal donor selection and screening for fecal microbiota transplantation: a review. Gut Microbes. (2017) 8:225-37. doi: 10.1080/19490976.2017.12 86006
124. Barnes D, Park KT. Donor considerations in fecal microbiota transplantation. Curr Gastroenterol Rep. (2017) 19:10. doi: 10.1007/s11894-017-0548-y

125. Woodworth MH, Neish EM, Miller NS, Dhere T, Burd EM, Carpentieri C, et al. Laboratory testing of donors and stool samples for fecal microbiota transplantation for recurrent Clostridium difficile infection. J Clin Microbiol. (2017) 55:1002-10. doi: 10.1128/JCM.02327-16

126. Tasnim N, Abulizi N, Pither J, Hart MM, Gibson DL. Linking the gut microbial ecosystem with the environment: does gut health depend on where we live? Front Microbiol. (2017) 8:1935. doi: 10.3389/fmicb.2017. 01935

127. Borody TJ. "Flora Power"- fecal bacteria cure chronic C. difficile diarrhea. Am J Gastroenterol. (2000) 95:3028-9. doi: 10.1111/j.1572-0241.2000.03277.x

128. Borody TJ, Warren EF, Leis SM, Surace R, Ashman O, Siarakas S. Bacteriotherapy using fecal flora: toying with human motions. J Clin Gastroenterol. (2004) 38:475-83. doi: 10.1097/01.mcg.0000128988.13808.dc

129. Lee $\mathrm{CH}$, Steiner $\mathrm{T}$, Petrof EO, Smieja M, Roscoe D, Nematallah A, et al. Frozen vs fresh fecal microbiota transplantation and clinical resolution of diarrhea in patients with recurrent clostridium difficile infection: a randomized clinical trial. JAMA. (2016) 315:142-9. doi: 10.1001/jama.2015.18098

130. Youngster I, Sauk J, Pindar C, Wilson RG, Kaplan JL, Smith MB, et al. Fecal microbiota transplant for relapsing Clostridium difficile infection using a frozen inoculum from unrelated donors: a randomized, open-label, controlled pilot study. Clin Infect Dis. (2014) 58:1515-22. doi: $10.1093 / \mathrm{cid} /$ ciu135

131. Kelly CR, Khoruts A, Staley C, Sadowsky MJ, Abd M, Alani M, et al. Effect of fecal microbiota transplantation on recurrence in multiply recurrent clostridium difficile infection: a randomized trial. Ann Intern Med. (2016) 165:609-16. doi: 10.7326/M16-0271

132. Jiang ZD, Ajami NJ, Petrosino JF, Jun G, Hanis CL, Shah M, et al. Randomised clinical trial: faecal microbiota transplantation for recurrent Clostridum difficile infection - fresh, or frozen, or lyophilised microbiota from a small pool of healthy donors delivered by colonoscopy. Aliment Pharmacol Ther. (2017) 45:899-908. doi: 10.1111/apt.13969

133. Hota SS, Sales V, Tomlinson G, Salpeter MJ, McGeer A, Coburn B, et al. Oral vancomycin followed by fecal transplantation versus tapering oral vancomycin treatment for recurrent clostridium difficile infection: an open-label, randomized controlled trial. Clin Infect Dis. (2017) 64:265-71. doi: $10.1093 / \mathrm{cid} / \mathrm{ciw} 731$

134. Wilson BC, Vatanen T, Cutfield WS, O'Sullivan JM. The super-donor phenomenon in fecal microbiota transplantation. Front Cell Infect Microbiol. (2019) 9:2. doi: 10.3389/fcimb.2019.00002

135. Vindigni SM, Surawicz CM. Fecal Microbiota Transplantation. Gastroenterol Clin N Am. (2017) 46:171-85. doi: 10.1016/j.gtc.2016.09.012

136. Fuentes S, de Vos WM. How to manipulate the microbiota: fecal microbiota transplantation. Adv Exp Med Biol. (2016) 902:143-53. doi: 10.1007/978-3-319-31248-4_10

137. Youngster I, Russell GH, Pindar C, Ziv-Baran T, Sauk J, Hohmann EL. Oral, capsulized, frozen fecal microbiota transplantation for relapsing Clostridium difficile infection. JAMA. (2014) 312:1772-8. doi: 10.1001/jama.2014. 13875

138. Ott SJ, Waetzig GH, Rehman A, Moltzau-Anderson J, Bharti R, Grasis JA, et al. Efficacy of sterile fecal filtrate transfer for treating patients with Clostridium difficile infection. Gastroenterology. (2017) 152:799-811 e7. doi: 10.1053/j.gastro.2016.11.010

139. Draper LA, Ryan FJ, Smith MK, Jalanka J, Mattila E, Arkkila PA, et al. Long-term colonisation with donor bacteriophages following successful faecal microbial transplantation. Microbiome. (2018) 6:220. doi: 10.1186/s40168-018-0598-x

140. Ramai D, Zakhia K, Ofosu A, Ofori E, Reddy M. Fecal microbiota transplantation: donor relation, fresh or frozen, delivery methods, cost-effectiveness. Ann Gastroenterol. (2019) 32:30-8. doi: 10.20524/aog.2018.0328

141. Kassam Z, Lee CH, Yuan Y, Hunt RH. Fecal microbiota transplantation for Clostridium difficile infection: systematic review and meta-analysis. Am J Gastroenterol. (2013) 108:500-8. doi: 10.1038/ajg.2013.59 
142. Terveer EM, van Beurden YH, Goorhuis A, Seegers J, Bauer MP, van Nood E, et al. How to: Establish and run a stool bank. Clin Microbiol Infect. (2017) 23:924-30. doi: 10.1016/j.cmi.2017.05.015

143. Goldenberg SD, Batra R, Beales I, Digby-Bell JL, Irving PM, Kellingray $\mathrm{L}$, et al. Comparison of different strategies for providing fecal microbiota transplantation to treat patients with recurrent Clostridium difficile infection in two english hospitals: a review. Infect Dis Ther. (2018) 7:71-86. doi: 10.1007/s40121-018-0189-y

144. Zhang F, Cui B, He X, Nie Y, Wu K, Fan D, et al. Microbiota transplantation: concept, methodology and strategy for its modernization. Protein Cell. (2018) 9:462-73. doi: 10.1007/s13238-018-0541-8

145. Kao D, Roach B, Silva M, Beck P, Rioux K, Kaplan GG, et al. Effect of oral capsule- vs colonoscopy-delivered fecal microbiota transplantation on recurrent Clostridium difficile infection: a randomized clinical trial. JAMA. (2017) 318:1985-93. doi: 10.1001/jama.2017. 17077

146. Rossen NG, MacDonald JK, de Vries EM, D’Haens GR, de Vos WM, Zoetendal EG, et al. Fecal microbiota transplantation as novel therapy in gastroenterology: a systematic review. World J Gastroenterol. (2015) 21:5359-71. doi: 10.3748/wjg.v21.i17.5359

147. Lloyd-Price J, Mahurkar A, Rahnavard G, Crabtree J, Orvis J, Hall $\mathrm{AB}$, et al. Strains, functions and dynamics in the expanded Human Microbiome Project. Nature. (2017) 550:61-6. doi: 10.1038/nature 23889

148. Paramsothy S, Paramsothy R, Rubin DT, Kamm MA, Kaakoush NO, Mitchell $\mathrm{HM}$, et al. Faecal microbiota transplantation for inflammatory bowel disease: a systematic review and meta-analysis. J Crohns Colitis. (2017) 11:1180-99. doi: 10.1093/ecco-jcc/jjx063

149. Borody TJ, Warren EF, Leis S, Surace R, Ashman O. Treatment of ulcerative colitis using fecal bacteriotherapy. J Clin Gastroenterol. (2003) 37:42-7. doi: 10.1097/00004836-200307000-00012

150. Kelly JR, Allen AP, Temko A, Hutch W, Kennedy PJ, Farid N, et al. Lost in translation? The potential psychobiotic Lactobacillus rhamnosus (JB-1) fails to modulate stress or cognitive performance in healthy male subjects. Brain Behav Immun. (2017) 61:50-9. doi: 10.1016/j.bbi.2016. 11.018

151. Weingarden AR, Vaughn BP. Intestinal microbiota, fecal microbiota transplantation, and inflammatory bowel disease. Gut Microbes. (2017) 8:238-52. doi: 10.1080/19490976.2017.12 90757

152. Kelly JR, Clarke G, Cryan JF, Dinan TG. Brain-gut-microbiota axis: challenges for translation in psychiatry. Ann Epidemiol. (2016) 26:366-72. doi: 10.1016/j.annepidem.2016.02.008

153. Vulevic J, Juric A, Tzortzis G, Gibson GR. A mixture of transgalactooligosaccharides reduces markers of metabolic syndrome and modulates the fecal microbiota and immune function of overweight adults. J Nutr. (2013) 143:324-31. doi: 10.3945/jn.112.1 66132

154. Cummings JH, Christie S, Cole TJ. A study of fructo oligosaccharides in the prevention of travellers' diarrhoea. Aliment Pharmacol Ther. (2001) 15:1139-45. doi: 10.1046/j.1365-2036.2001. 01043.x

155. Paramsothy S, Kamm MA, Kaakoush NO, Walsh AJ, van den Bogaerde J, Samuel D, et al. Multidonor intensive faecal microbiota transplantation for active ulcerative colitis: a randomised placebocontrolled trial. Lancet. (2017) 389:1218-28. doi: 10.1016/S0140-6736(17) 30182-4

156. Tian H, Ge X, Nie Y, Yang L, Ding C, McFarland LV, et al. Fecal microbiota transplantation in patients with slow-transit constipation: a randomized, clinical trial. PLoS ONE. (2017) 12:e0171308. doi: 10.1371/journal.pone.01 71308

157. Kang DW, Adams JB, Gregory AC, Borody T, Chittick L, Fasano A, et al. Microbiota Transfer Therapy alters gut ecosystem and improves gastrointestinal and autism symptoms: an openlabel study. Microbiome. (2017) 5:10. doi: 10.1186/s40168-01 6-0225-7

158. Kakihana K, Fujioka Y, Suda W, Najima Y, Kuwata G, Sasajima S, et al. Fecal microbiota transplantation for patients with steroid-resistant acute graft-versus-host disease of the gut. Blood. (2016) 128:2083-8. doi: 10.1182/blood-2016-05-717652

159. Wang S, Xu M, Wang W, Cao X, Piao M, Khan S, et al. Systematic review: adverse events of fecal microbiota transplantation. PLoS ONE. (2016) 11:e0161174. doi: 10.1371/journal.pone.01 61174

160. Qazi T, Amaratunga T, Barnes EL, Fischer M, Kassam Z, Allegretti JR. The risk of inflammatory bowel disease flares after fecal microbiota transplantation: systematic review and meta-analysis. Gut Microbes. (2017) 8:574-88. doi: 10.1080/19490976.2017.13 53848

161. Alang N, Kelly CR. Weight gain after fecal microbiota transplantation. Open Forum Infect Dis. (2015) 2:ofv004. doi: 10.1093/ofid/o fv004

162. Agrawal M, Aroniadis OC, Brandt LJ, Kelly C, Freeman S, Surawicz C, et al. The long-term efficacy and safety of fecal microbiota transplant for recurrent, severe, and complicated Clostridium difficile infection in 146 elderly individuals. J Clin Gastroenterol. (2016) 50:403-7. doi: 10.1097/MCG.0000000000000410

163. Cammarota G, Ianiro G, Tilg H, Rajilic-Stojanovic M, Kump P, Satokari R, et al. European consensus conference on faecal microbiota transplantation in clinical practice. Gut. (2017) 66:569-80. doi: 10.1136/gutjnl-2016-3 13017

164. Quera R, Espinoza R, Estay C, Rivera D. Bacteremia as an adverse event of fecal microbiota transplantation in a patient with Crohn's disease and recurrent Clostridium difficile infection. J Crohn Colitis. (2014) 8:252-3. doi: 10.1016/j.crohns.2013.10.002

165. De Leon LM, Watson JB, Kelly CR. Transient flare of ulcerative colitis after fecal microbiota transplantation for recurrent Clostridium difficile infection. Clin Gastroenterol Hepatol. (2013) 11:1036-8. doi: 10.1016/j.cgh.2013.04.045

166. Atarashi K, Tanoue T, Shima T, Imaoka A, Kuwahara T, Momose Y, et al. Induction of colonic regulatory $\mathrm{T}$ cells by indigenous Clostridium species. Science. (2011) 331:337-41. doi: 10.1126/science.1198469

167. Atarashi K, Tanoue T, Oshima K, Suda W, Nagano Y, Nishikawa H, et al. Treg induction by a rationally selected mixture of Clostridia strains from the human microbiota. Nature. (2013) 500:232-6. doi: 10.1038/nature 12331

168. Furusawa Y, Obata Y, Fukuda S, Endo TA, Nakato G, Takahashi D, et al. Commensal microbe-derived butyrate induces the differentiation of colonic regulatory T cells. Nature. (2013) 504:446-50. doi: 10.1038/nature12721

169. Duplessis CA, You D, Johnson M, Speziale A. Efficacious outcome employing fecal bacteriotherapy in severe Crohn's colitis complicated by refractory Clostridium difficile infection. Infection. (2012) 40:469-72. doi: 10.1007/s15010-01 $1-0226-1$

170. Wang ZK, Yang YS, Chen Y, Yuan J, Sun G, Peng LH. Intestinal microbiota pathogenesis and fecal microbiota transplantation for inflammatory bowel disease. World J Gastroenterol. (2014) 20:14805-20. doi: 10.3748/wjg.v20.i40. 14805

171. Taur Y, Coyte K, Schluter J, Robilotti E, Figueroa C, Gjonbalaj M, et al. Reconstitution of the gut microbiota of antibiotic-treated patients by autologous fecal microbiota transplant. Sci Trans Med. (2018) 10:460. doi: 10.1126/scitranslmed.aap9489

172. Suez J, Zmora N, Zilberman-Schapira G, Mor U, Dori-Bachash M, Bashiardes $\mathrm{S}$, et al. Post-antibiotic gut mucosal microbiome reconstitution is impaired by probiotics and improved by autologous FMT. Cell. (2018) 174:1406-23 e16. doi: 10.1016/j.cell.2018.08.047

173. Bulow C, Langdon A, Hink T, Wallace M, Reske KA, Patel S, et al. Impact of amoxicillin-clavulanate followed by autologous fecal microbiota transplantation on fecal microbiome structure and metabolic potential. mSphere. (2018) 3:6. doi: 10.1128/mSphereDirect.00 588-18

174. Konijeti GG, Sauk J, Shrime MG, Gupta M, Ananthakrishnan AN. Cost-effectiveness of competing strategies for management of recurrent Clostridium difficile infection: a decision analysis. Clin Infect Dis. (2014) 58:1507-14. doi: 10.1093/cid/ciu128

175. Varier RU, Biltaji E, Smith KJ, Roberts MS, Kyle Jensen M, LaFleur J, et al. Cost-effectiveness analysis of fecal microbiota transplantation for 
recurrent Clostridium difficile infection. Infect Control Hosp Epidemiol. (2015) 36:438-44. doi: 10.1017/ice.2014.80

176. Merlo G, Graves N, Brain D, Connelly LB. Economic evaluation of fecal microbiota transplantation for the treatment of recurrent Clostridium difficile infection in Australia. J Gastroenterol Hepatol. (2016) 31:1927-32. doi: 10.1111/jgh.13402

177. Varier RU, Biltaji E, Smith KJ, Roberts MS, Jensen MK, LaFleur J, et al. Cost-effectiveness analysis of treatment strategies for initial Clostridium difficile infection. Clin Microbiol Infect. (2014) 20:1343-51. doi: 10.1111/1469-0691.12805

178. Juul FE, Garborg K, Bretthauer M, Skudal H, Oines MN, Wiig H, et al. Fecal Microbiota Transplantation for Primary Clostridium difficile Infection. $N$ Engl J Med. (2018) 378:2535-6. doi: 10.1056/NEJMc1 803103

179. Expert Panel on Detection E, Treatment of High Blood Cholesterol in A. Executive Summary of The Third Report of The National Cholesterol Education Program (NCEP) Expert Panel on Detection, Evaluation, And Treatment of High Blood Cholesterol In Adults (Adult Treatment Panel III). JAMA. (2001) 285:2486-97. doi: 10.1001/jama.285. 19.2486

180. Alberti KG, Eckel RH, Grundy SM, Zimmet PZ, Cleeman JI, Donato KA, et al. Harmonizing the metabolic syndrome: a joint interim statement of the International Diabetes Federation Task Force on Epidemiology and Prevention; National Heart, Lung, and Blood Institute; American Heart Association; World Heart Federation; International Atherosclerosis Society; and International Association for the Study of Obesity. Circulation. (2009) 120:1640-5. doi: 10.1161/CIRCULATIONAHA.109. 192644

181. Le Bastard Q, Ward T, Sidiropoulos D, Hillmann BM, Chun CL, Sadowsky $\mathrm{MJ}$, et al. Fecal microbiota transplantation reverses antibiotic and chemotherapy-induced gut dysbiosis in mice. Sci Rep. (2018) 8:6219. doi: $10.1038 / \mathrm{s} 41598-018-24342-\mathrm{x}$

182. Kaito S, Toya $\mathrm{T}$, Yoshifuji $\mathrm{K}$, Kurosawa $\mathrm{S}$, Inamoto $\mathrm{K}$, Takeshita $\mathrm{K}$, et al. Fecal microbiota transplantation with frozen capsules for a patient with refractory acute gut graft-versus-host disease. Blood Adv. (2018) 2:3097-101. doi: 10.1182/bloodadvances.20180 24968

183. Guyton K, Alverdy JC. The gut microbiota and gastrointestinal surgery. Nat Rev Gastroenterol Hepatol. (2017) 14:43-54. doi: 10.1038/nrgastro.20 16.139

184. Lichtman JS, Ferreyra JA, Ng KM, Smits SA, Sonnenburg JL, Elias JE. Hostmicrobiota interactions in the pathogenesis of antibiotic-associated diseases. Cell Rep. (2016) 14:1049-61. doi: 10.1016/j.celrep.2016.01.009

185. Ferrer M, Martins dos Santos VA, Ott SJ, Moya A. Gut microbiota disturbance during antibiotic therapy: a multi-omic approach. Gut Microbes. (2014) 5:64-70. doi: 10.4161/gmic.27128

Conflict of Interest Statement: EE is a paid consultant at DayTwo and BiomX.

The remaining authors declare that the research was conducted in the absence of any commercial or financial relationships that could be construed as a potential conflict of interest.

Copyright (c) 2019 Leshem, Horesh and Elinav. This is an open-access article distributed under the terms of the Creative Commons Attribution License (CC BY). The use, distribution or reproduction in other forums is permitted, provided the original author(s) and the copyright owner(s) are credited and that the original publication in this journal is cited, in accordance with accepted academic practice. No use, distribution or reproduction is permitted which does not comply with these terms. 